\title{
Winter Atmospheric Buoyancy Forcing and Oceanic Response during Strong Wind Events around Southeastern Greenland in the Regional Arctic System Model (RASM) for 1990-2010*
}

\author{
Alice K. DuVivier, ${ }^{+, \#}$ John J. CAssano, ${ }^{+, \#}$ Anthony Craig, ${ }^{@}$ Joseph Hamman, ${ }^{\&}$ Wieslaw \\ MASLOWSKI,${ }^{@}$ BART NIJSSEN, ${ }^{\&}$ ROBERT OSINSKI, ${ }^{@}, * *$ AND ANDREW ROBERTs ${ }^{@}$ \\ ${ }^{+}$Cooperative Institute for Research in Environmental Sciences, Boulder, Colorado \\ \# Department of Atmospheric and Oceanic Sciences, University of Colorado, Boulder, Boulder, Colorado \\ ${ }^{\circledR}$ Naval Postgraduate School, Monterey, California \\ ${ }^{\&}$ Department of Civil and Environmental Engineering, University of Washington, Seattle, Washington \\ ** Institute of Oceanology, Polish Academy of Sciences, Sopot, Poland
}

(Manuscript received 21 August 2015, in final form 7 November 2015)

\begin{abstract}
Strong, mesoscale tip jets and barrier winds that occur along the southeastern Greenland coast have the potential to impact deep convection in the Irminger Sea. The self-organizing map (SOM) training algorithm was used to identify 12 wind patterns that represent the range of winter [November-March (NDJFM)] wind regimes identified in the fully coupled Regional Arctic System Model (RASM) during 1990-2010. For all wind patterns, the ocean loses buoyancy, primarily through the turbulent sensible and latent heat fluxes; haline contributions to buoyancy change were found to be insignificant compared to the thermal contributions. Patterns with westerly winds at the Cape Farewell area had the largest buoyancy loss over the Irminger and Labrador Seas due to large turbulent fluxes from strong winds and the advection of anomalously cold, dry air over the warmer ocean. Similar to observations, RASM simulated typical ocean mixed layer depths (MLD) of approximately $400 \mathrm{~m}$ throughout the Irminger basin, with individual years experiencing MLDs of $800 \mathrm{~m}$ or greater. The ocean mixed layer deepens over most of the Irminger Sea following wind events with northerly flow, and the deepening is greater for patterns of longer duration. Seasonal deepest MLD is strongly and positively correlated to the frequency of westerly tip jets with northerly flow.
\end{abstract}

\section{Introduction}

Wintertime synoptic storms interact with the steep topography along Greenland's southeastern coast and generate mesoscale tip jets (Doyle and Shapiro 1999; Moore 2003; Våge et al. 2009b; Moore 2012, 2014) and barrier winds (Moore and Renfrew 2005; Harden et al. 2011). During these winter wind events, the combination of strong winds and large temperature and moisture gradients between the cold, dry air and the warmer ocean surface drive oceanic energy and buoyancy loss

\footnotetext{
* Supplemental information related to this paper is available at the Journals Online website: http://dx.doi.org/10.1175/JCLI-D-150592.s1.

Corresponding author address: Alice K. DuVivier, University of Colorado, 216 UCB, Boulder, CO 80309.

E-mail: alice.duvivier@colorado.edu
}

(Petersen and Renfrew 2009; Renfrew et al. 2009; Harden et al. 2011; DuVivier and Cassano 2013; Oltmanns et al. 2014). Such conditions are favorable to open-ocean convection, or sinking of surface ocean water, which is a localized process that only occurs in a few locations worldwide (Marshall and Schott 1999). Cyclonic circulation preconditions the ocean by weakening vertical stability, and subsequent heat loss and increase of density causes the water to sink (Killworth 1983; Marshall and Schott 1999). In this paper, we investigate the impact of high-wind events on the seas bordering Greenland's southern coasts, including the Labrador and Irminger Seas, as shown in the boxed region in Fig. 1.

The Labrador Sea has a cyclonic circulation and is a well-known area of open-ocean convection and deepwater formation (Clarke and Gascard 1983; Gascard and Clarke 1983; Marshall and Schott 1999; McGeehan and Maslowski 2011). More recently, convection in the 
a)

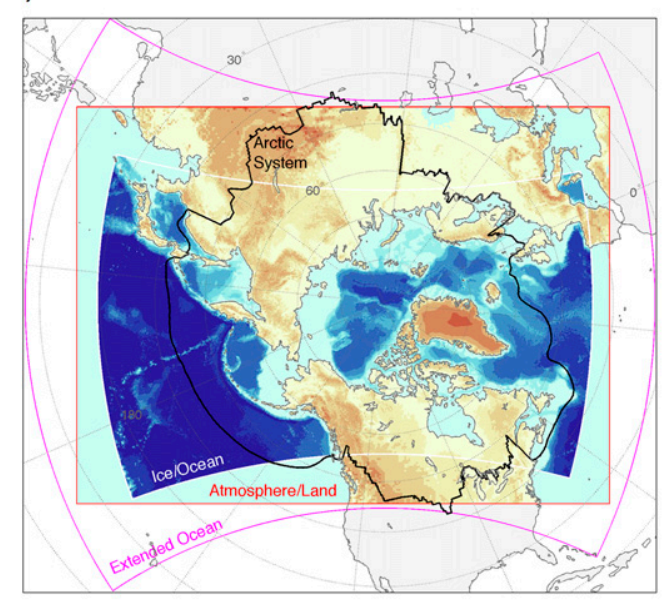

b)

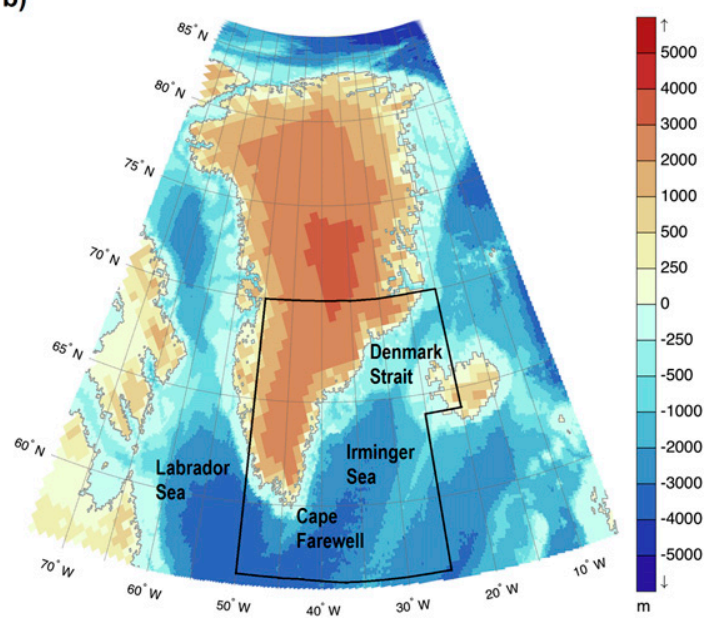

FIG. 1. (a) Map of terrain height and bathymetry (m) for the pan-Arctic RASM domain with boundaries of the $50-\mathrm{km}$ atmosphere-land domain (red), boundaries of the $\sim 9-\mathrm{km}$ ice-ocean domain (dark blue and bathymetry), boundaries of the $\sim 9-\mathrm{km}$ extended ocean domain (magenta), and boundaries of the Arctic system as defined in Roberts et al. (2010) (black). (b) Terrain height and bathymetry (m) for the Greenland focus region with the SOM training area is bounded in black.

Irminger Sea has also been investigated. The Irminger Sea has a cyclonic circulation driven by positive wind stress curl from the strong mesoscale wind events that take place during the winter (Spall and Pickart 2003; Pickart et al. 2003a; Våge et al. 2011), and convection has been observed there to depths of 400-1000 m (Bacon et al. 2003; Våge et al. 2009a, 2011; De Jong et al. 2012). Mesoscale westerly tip jets have been a focus of investigation for forcing ocean convection (Pickart et al. 2003a; Spall and Pickart 2003; Våge et al. 2008, 2009b, 2011), and westerly tip jets may also be important for both preconditioning and convection in the Irminger Sea and southeastern Labrador Sea due to the strong positive wind stress curl during wind events (Lavender et al. 2002; Martin and Moore 2007; Sproson et al. 2008; Pickart et al. 2008; Oltmanns et al. 2014).

To date, ocean model studies of convection in the seas around Greenland have used simplified or standalone ocean models, have focused on short time periods, or are limited in geographical domain. An idealized regional ocean model study shows convection is possible during westerly tip jets (Pickart et al. 2003a), and a simple one-dimensional (1D) ocean model requires a tip jet parameterization to replicate observed ocean mixed layer depths (Våge et al. 2008). A one-month case study shows the modeled ocean response to barrier wind events depends on the resolution of atmospheric forcing data (Haine et al. 2009), and the use of high-resolution atmospheric forcing can increase the Atlantic meridional overturning circulation (Jung et al. 2014; Holdsworth and
Myers 2015). These results suggest that mesoscale wind events are crucial for forcing ocean convection, yet mesoscale winds around Greenland are not accurately represented in global-scale atmospheric models because of the coarse spatial resolution (Kolstad 2008; Sproson et al. 2010) or in atmospheric reanalyses used to force standalone ocean models. As a result, parameterizations of strong mesoscale winds have been developed for use with lowresolution atmospheric forcing (Våge et al. 2008; Sproson et al. 2010; Condron and Renfrew 2013). The earth system is holistic, so the surface temperature affects the near-surface winds, which in turn drive fluxes that affect the surface temperature. This is one reason that using a fully coupled model is so important-the earth system components evolve together rather than uncoupled model responses to fixed boundary conditions that do not change as they would in reality. Using a parameterization provides a way to represent the impact of the winds on ocean processes, but explicitly representing winds is more desirable in that it captures the interaction between wind, air and surface temperatures, and turbulent fluxes in a physically consistent manner. Explicitly simulating mesoscale winds requires high-resolution atmospheric models (DuVivier and Cassano 2013; Shkolnik and Efimov 2013; Tilinina et al. 2014) with $50-\mathrm{km}$ resolution or higher to capture the steep topographic gradients necessary to realistically block airflow and drive strong wind events (DuVivier and Cassano 2013). 
In this study, we use self-organizing maps (SOM) to identify 12 near-surface wind patterns around southeastern Greenland that represent the range of wind regimes present during twenty winters [NovemberMarch (NDJFM) 1990-2010] simulated by the fully coupled Regional Arctic System Model (RASM). By using a high-resolution, fully coupled model in which the atmosphere, ice, and ocean evolve together with two-way air-sea interactions, we can explore a realistic ocean response to a large number of different wind events. We examine the thermodynamic ocean buoyancy forcing and response of the ocean mixed layer depth (MLD) for the 12 wind patterns. The paper is organized as follows: the RASM data, SOM pattern classification method, and buoyancy flux calculation are explained in section 2. In section 3, we explore the contributions to the buoyancy flux for each wind pattern, and in section 4 we address the ocean MLD response to wind patterns and address the importance of wind event duration for changes in MLD. Section 5 discusses implications of this study and future directions for exploration.

\section{Data and methods}

\section{a. RASM}

RASM is a fully coupled atmosphere-ocean-sea ice-land limited-area model (Maslowski et al. 2012) configured on the pan-Arctic domain shown in Fig. 1a. Here, we describe aspects of RASM relevant to this study, and additional details can be found in Roberts et al. (2015). RASM is composed of the Weather Research and Forecasting (WRF) Model, the Los Alamos National Laboratory Parallel Ocean Program (POP) and Sea Ice Model (CICE), the Variable Infiltration Capacity (VIC) land surface model (Hamman et al. 2015, manuscript submitted to J. Climate), and the streamflow routing VIC (RVIC) model (J. Hamman et al. 2015, unpublished manuscript). Surface fluxes are exchanged every 20 min using the same flux coupler as the Community Earth System Model (CESM), version 1.1 (Craig et al. 2012), with modifications in RASM for improved ice-ocean dynamics (Roberts et al. 2015). The pan-Arctic domain encompasses the Arctic system, as defined by Roberts et al. (2010), and extends to the North Pacific and North Atlantic Oceans to account for passage of cyclones into the Arctic. The WRF and VIC models share a $50-\mathrm{km}$ polar stereographic grid, while POP and CICE share a $1 / 12^{\circ}$ $(\sim 9 \mathrm{~km})$ rotated sphere grid with the equator passing through the North Pole. Multidecadal simulations with adequate resolution for simulating mesoscale wind features (DuVivier and Cassano 2013) are possible when using RASM on high performance computing architectures.

RASM uses the WRF Model, version 3.2 (Skamarock et al. 2008), that has been modified to allow for coupling other climate model components in RASM. The WRF Model physics parameterizations and modifications used in this configuration of RASM are shown in Table 1. In RASM, the WRF Model uses 2.5 -min time steps and is coupled every $20 \mathrm{~min}$ through the aggregate averages of 2.5-min fluxes from the WRF Model to the surface. Lateral and upperboundary conditions for the WRF Model are provided by ERA-Interim (Dee et al. 2011), while lowerboundary conditions and sea ice conditions that would normally be necessary for the WRF Model are not needed when it is coupled in RASM because these data are received via the coupler from the land, ocean, and sea ice models. The WRF Model has 40 vertical levels, with the lowest model level at approximately $12 \mathrm{~m}, 10$ levels within $1 \mathrm{~km}$ above the ocean, and a 50-hPa model top. To constrain the large-scale circulation but still allow for free evolution of the boundary layer system (Cassano et al. 2011), planetary-scale temperature and wind fields are spectrally nudged beginning at eta level $20(\sim 500 \mathrm{hPa})$ with a strength of zero that is linearly ramped up to $0.0003 \mathrm{~s}^{-1}$ at the top of the atmosphere (for details see Skamarock et al. 2008).

The ocean model in RASM (POP) is the same version as in CESM, version 1.1, and has been modified to run regionally on the pan-Arctic $1 / 12^{\circ}(\sim 9 \mathrm{~km})$ rotated spherical coordinate, eddy-permitting grid. POP has 45 vertical levels, with 7 levels in the upper $42 \mathrm{~m}$ and 19 levels in the upper $500 \mathrm{~m}$. Surface freshwater runoff from land surfaces, including Greenland, is provided to POP from the VIC model via the RVIC model (J. Hamman et al. 2015, unpublished manuscript). POP uses $K$-profile parameterization for vertical mixing (Large et al. 1994), and the POP model's MLD variable $(\mathrm{hmxl})$ is used for analysis in this study. The sea ice model, CICE version 4 (Hunke and Lipscomb 2010), is configured on the same domain as POP and with five predictive sea ice thickness categories. Details specific to the modifications and initial conditions of POP and CICE within RASM can be found in Roberts et al. (2015). To analyze a time period for which the ice-ocean system has adjusted to the atmospheric forcing within the fully coupled RASM, we have started the coupled model spinup from 1 September 1979 to 31 October 1990 but do not analyze this early time period here. 
TABLE 1. WRF Model physics and modifications used in this configuration of RASM.

\begin{tabular}{|c|c|c|}
\hline & RASM physical parameterization & RASM physics modification(s) \\
\hline $\begin{array}{l}\text { Longwave } \\
\text { radiation }\end{array}$ & $\begin{array}{l}\text { Rapid Radiative Transfer Model } \\
\text { for GCMs (RRTMG; } \\
\text { Iacono et al. 2008) }\end{array}$ & $\begin{array}{l}\text { - Utilizes upward longwave radiation passed from } \\
\text { coupler. } \\
\text { - Droplet sizes predicted from microphysics. }\end{array}$ \\
\hline $\begin{array}{l}\text { Shortwave } \\
\text { radiation }\end{array}$ & RRTMG (Iacono et al. 2008) & $\begin{array}{l}\text { - Spectral albedos that are portioned into two } \\
\text { bands, divided at } 700 \mathrm{~nm} \text {, as described by } \\
\text { Holland et al. (2012). } \\
\text { - Droplet sizes predicted from microphysics. }\end{array}$ \\
\hline $\begin{array}{l}\text { Cloud } \\
\text { microphysics }\end{array}$ & $\begin{array}{l}\text { Morrison two-moment (Morrison } \\
\text { et al. 2009) }\end{array}$ & $\begin{array}{l}\text { - Predicted ice and water droplet sizes coupled to } \\
\text { radiation. } \\
\text { - Droplet concentration set to constant values } \\
\text { appropriate for Arctic over land }\left(200 \mathrm{~cm}^{-3}\right) \\
\text { and ocean }\left(50 \mathrm{~cm}^{-3}\right) \text {. }\end{array}$ \\
\hline $\begin{array}{l}\text { Cumulus } \\
\text { clouds }\end{array}$ & $\begin{array}{l}\text { Grell-Devenyi (Grell and Dévényi } \\
\text { 2002) }\end{array}$ & None \\
\hline Boundary layer & $\begin{array}{l}\text { Yonsei University (YSU; } \\
\text { Hong et al. 2006) }\end{array}$ & None \\
\hline Surface layer & $\begin{array}{l}\text { MM5 similarity theory (Paulson 1970; } \\
\text { Dyer and Hicks 1970; Webb 1970) }\end{array}$ & $\begin{array}{l}\text { - Utilizes surface roughness, friction velocity, } \\
\text { latent heat flux, and sensible heat flux passed } \\
\text { from the coupler. } \\
\text { - Surface stability determined by inverting fluxes } \\
\text { passed by coupler. }\end{array}$ \\
\hline
\end{tabular}

This study uses daily averaged WRF, POP, and CICE output for 20 winter seasons (defined as November through March) from 1990 to 2010. The 20 winter seasons capture interannual variability in the large-scale atmospheric circulation and resulting ocean forcing. In this study we will focus only on the wind patterns and surface fluxes around southern Greenland, including the Irminger Sea, Labrador Sea, and Denmark Strait (Fig. 1b). The ice edge modeled in RASM as defined by the $15 \%$ sea ice concentration and mean ice thickness greater than $10 \mathrm{~cm}$ (not shown) is consistent with the satellite observed sea ice edge. However, to keep the focus of this paper on the air-sea interactions over the open ocean and to minimize the impact of sea ice growth or melt on surface fluxes, we only analyze areas of open ocean with a modeled sea ice concentration of $15 \%$ or less.

\section{b. Wind pattern classification}

This study uses the SOM neural network algorithm to identify near-surface wind patterns around southeastern Greenland and assess the ocean response to forcing associated with each type of pattern. The SOM training algorithm is an unsupervised, iterative process that identifies a user-specified number of representative patterns within a dataset (Kohonen 2001; Hewitson and Crane 2002; Cassano et al. 2007) and arranges similar patterns (or nodes) together into a two-dimensional array, or SOM, where the linear distance between patterns signifies the similarity between representative patterns, as described in Schuenemann et al. (2009). The SOM method has been shown to be a robust method for identifying dominant weather patterns (Reusch et al. 2005; Liu et al. 2006; Sheridan and Lee 2011).

This project uses wintertime (NDJFM) winds in the SOM training algorithm because the strongest mesoscale winds around southeastern Greenland occur in the winter from November through March (Moore 2003), and the largest deepening in oceanic mixed layer takes place over this same time period. The training data used are the 1990-2010 winter daily average (3020 days total) zonal and meridional wind components from the lowest WRF Model level $(\sim 12 \mathrm{~m})$. Additionally, only data from grid cells that occur over the ocean near the southeastern Greenland coast (boxed region on Fig. 1b) were used so that the SOM algorithm identifies patterns based on the speed and direction of mesoscale wind features that directly influence the ocean. Different SOM sizes (columns $\times$ rows: $4 \times 2,4 \times 3,5 \times 4,6 \times 4,6 \times 5,7 \times 5$, and $8 \times 6$ ) and training parameters were evaluated (Hewitson and Crane 2002; Cassano et al. 2015), and the SOM for each size was chosen to minimize the 

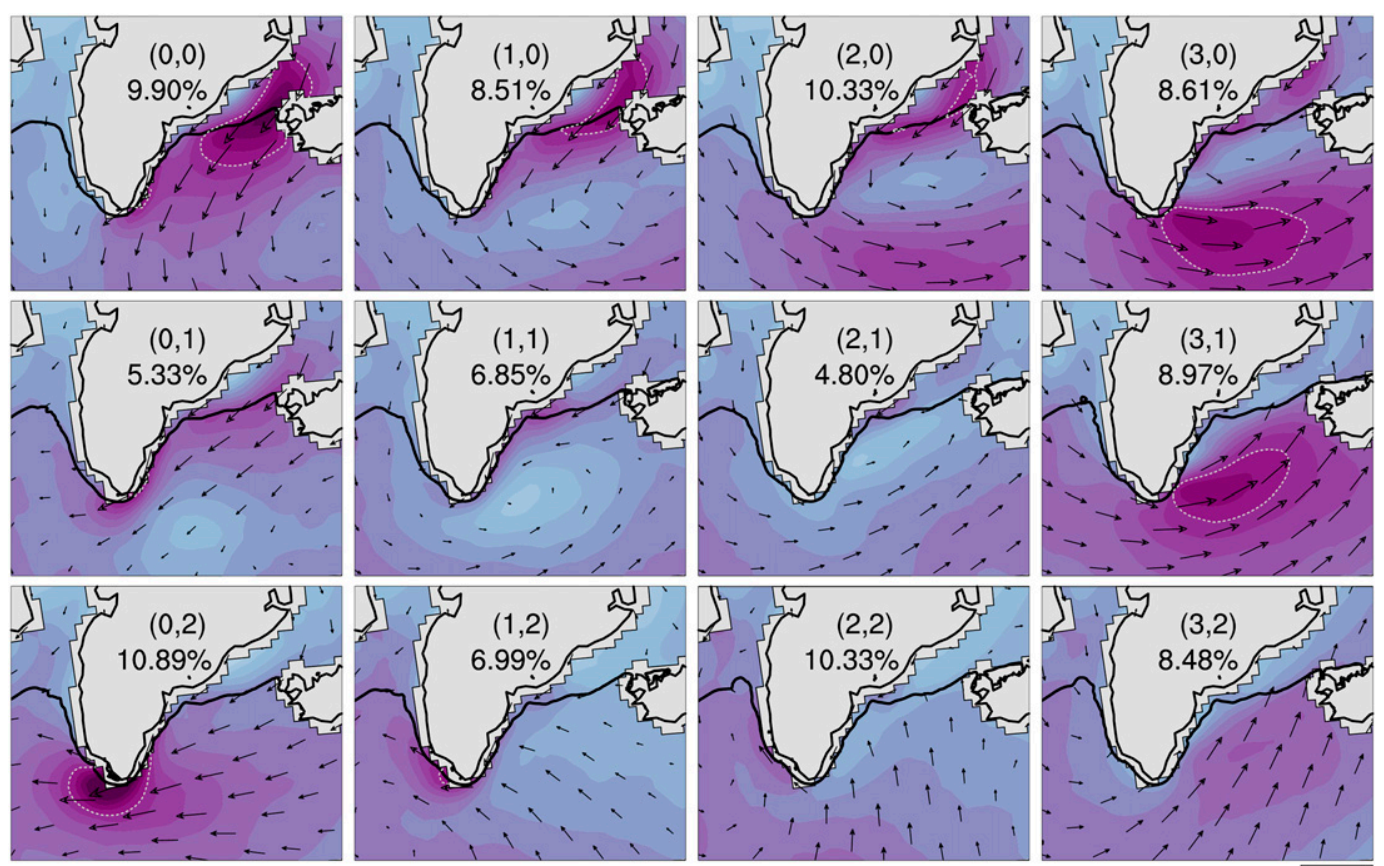

$\underset{\mathrm{m} \mathrm{s}}{\rightarrow}$

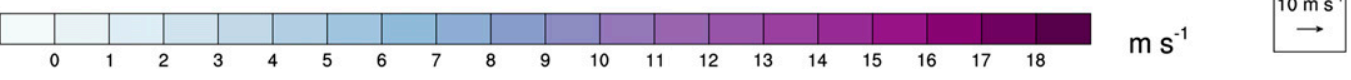

FIG. 2. RASM composite wind speed $\left(\mathrm{m} \mathrm{s}^{-1}\right)$ and wind vectors for each of the 12 representative wintertime (NDJFM) wind patterns identified by the SOM for 1990-2010. The frequency of occurrence of each pattern is indicated by the percentage below the pattern number. The dashed gray contour shows the $15 \mathrm{~m} \mathrm{~s}^{-1}$ wind speed. The dark black contour represents the average $15 \%$ sea ice contour modeled by CICE in RASM for each pattern.

root-mean-squared difference (RMSD) between the patterns identified and the data used in the training algorithm.

A detailed explanation on how to select the number of patterns that should be used in an SOM analysis is found in Reusch et al. (2005) or Cassano et al. (2015). Previous work has investigated the subtle differences in wind patterns and the resulting turbulent fluxes around southeastern Greenland (DuVivier and Cassano 2015a,b). In contrast, this manuscript seeks to understand the ocean response to the dominant wind patterns in this region, and a $4 \times 3$ SOM (Fig. 2) was selected for analysis because it captures the dominant wind patterns present around Greenland. In larger SOM arrays the wind patterns have subtle variations that are not scientifically significant for determining the ocean response to the winds over a 20 -yr period. The data from each of the 3020 days used in the training algorithm were then mapped to one of the 12 representative patterns based on the minimum RMSD between that day's average wind vectors and the representative wind vectors in the $\mathrm{SOM}$; the average RMSD for the $4 \times 3 \mathrm{SOM}$ is $2.7 \mathrm{~m} \mathrm{~s}^{-1}$. A composite of atmospheric or oceanic variables (i.e., wind speed, 2-m temperature, sea surface temperature, etc.) is calculated by averaging all events that map to a particular pattern. The pattern frequency is defined as the ratio of the number of days that map to a particular pattern relative to the 3020 days used for training the SOM.

The composite zonal and meridional wind components and wind speed for the SOM and pattern frequencies are shown in Fig. 2. The SOM is arranged such that patterns with northerly, barrier-parallel winds from the Denmark Strait to Cape Farewell are in the top row, while patterns with southerly or weak coastal winds are in the bottom row. The left columns show easterly flow at Cape Farewell, while the right columns show westerly flow at Cape Farewell. The patterns with the largest differences from one another map to the corners of the SOM and tend to be the most extreme, while transitional patterns occur near the center of the SOM. The patterns in the four corners of the SOM, which were objectively identified during SOM training, correspond to the northeasterly, southeasterly, northwesterly, and southwesterly subtypes of tip jets described in Moore (2014). 
TABLE 2. Constants used in buoyancy flux calculation [Eq. (1)].

\begin{tabular}{|c|c|}
\hline Value & Description \\
\hline$\alpha_{T}=1 \times 10^{-4 \circ} \mathrm{C}^{-1}$ & $\begin{array}{l}\text { Thermal expansion coefficient } \\
\text { for seawater (Marshall } \\
\text { and Plumb 2007, Table 9.4) }\end{array}$ \\
\hline$\beta=7.8 \times 10^{-4} \mathrm{~kg} \mathrm{~g}^{-1}$ & $\begin{array}{l}\text { Saline contraction coefficient } \\
\text { for seawater (Marshall and } \\
\text { Plumb 2007, Table 9.4) }\end{array}$ \\
\hline$g=9.81 \mathrm{~m} \mathrm{~s}^{-1}$ & Gravitational constant \\
\hline$\rho_{\text {ref }}=1000 \mathrm{~kg} \mathrm{~m}^{-3}$ & Density of freshwater \\
\hline$c_{w}=4.18 \times 10^{3} \mathrm{~J} \mathrm{~kg}^{-1{ }^{\circ} \mathrm{C}^{-1}}$ & Specific heat of freshwater \\
\hline
\end{tabular}

\section{c. Buoyancy flux}

To understand how the atmosphere impacts the surface ocean buoyancy, we use POP model data to calculate the surface buoyancy flux $B\left(\mathrm{~m}^{2} \mathrm{~s}^{-3}\right)$ out of the ocean [following Marshall and Plumb (2007), Eq. (114)]:

$$
\begin{aligned}
B= & \frac{g}{\rho_{\text {ref }}}\left\{\left[\frac{\alpha_{T}}{c_{w}}\left(Q_{\mathrm{Lat}}+Q_{\mathrm{Sen}}+Q_{\mathrm{LW}}+Q_{\mathrm{SW}}\right)\right]\right. \\
& \left.+\left[\rho_{\mathrm{ref}} \beta S(E-P)\right]\right\},
\end{aligned}
$$

where $Q_{\mathrm{Lat}}$ is the latent heat flux (LHF) at the ocean's surface, and $Q_{\text {Sen }}$ is the sensible heat flux (SHF) at the ocean's surface. Both turbulent fluxes depend on the scalar wind speed at the lowest WRF Model level and the moisture and temperature gradient between the lowest WRF Model level and the ocean surface (DuVivier and Cassano 2013). The net longwave flux at the ocean's surface is represented by $Q_{\mathrm{LW}} ; Q_{\mathrm{Sw}}$ is the net shortwave flux at the ocean's surface. For all thermal term components ( $Q_{\mathrm{Lat}}, Q_{\mathrm{Sen}}, Q_{\mathrm{LW}}$, and $Q_{\mathrm{SW}}$ ), positive values indicate buoyancy loss from the ocean and gain by the atmosphere. The haline term components include the surface salinity $S$, the evaporation $E$, and the precipitation $P$. A positive net haline term indicates buoyancy loss from the ocean, while a negative haline term indicates buoyancy gain. A positive buoyancy flux indicates a decrease in buoyancy for surface ocean waters and may lead to convection due to increased density of the surface water. All other terms in Eq. (1) are detailed in Table 2.

\section{Buoyancy forcing from atmosphere}

\section{a. Net buoyancy flux}

For all winter wind patterns there is a net loss of buoyancy out of the ocean (Fig. 3), as calculated from Eq. (1) and POP model output. The buoyancy loss field from the ocean spatially resembles the maximum wind speed for each pattern (Fig. 2), which indicates a relationship between the oceanic buoyancy loss and the wind speed. Patterns with northerly, barrier flow (Fig. 3, top row) have the maximum buoyancy loss along the ice edge where there are strong winds and cold, dry air first encounters the relatively warmer ocean surface. The magnitude of buoyancy loss decreases with distance from the ice edge. Patterns with southerly flow (Fig. 3, bottom row) also remove buoyancy from the ocean, but the magnitude of buoyancy loss is smaller than for patterns with northerly flow. Additionally, easterly tip jet patterns (Fig. 3, left column) have a local maximum of buoyancy loss just west of Cape Farewell. Westerly tip jets (Fig. 3, right columns) have similar magnitude buoyancy loss along the ice edge and in the core of the atmospheric jet that occurs over the ocean east of Cape Farewell, and they also have large buoyancy loss in the Labrador Sea. This finding is consistent with those of Moore et al. (2014), who found that the maximum energy loss from turbulent fluxes in the Labrador Sea is related to Greenland's topographic influence on the upstream wind field over the Labrador Sea.

The individual contributions of the thermal and haline terms to the total buoyancy flux are shown in Table 3 (columns in boldface). The percent contribution was computed at each open-ocean grid point and averaged into a single value. The spatial fields associated with each term of the total buoyancy flux and that are used to calculate the values found in Table 3 can be found in the supplementary material (Figs. S1-S8: thermal term, LHF, SHF, net longwave radiation, net shortwave radiation, haline term, evaporation, and precipitation).

The thermal term is three orders of magnitude larger than the haline term for all wind patterns and dominates the net buoyancy loss (Table 3 ). The contributions of the individual constituents to the thermal term (LHF, SHF, net longwave radiation, and net shortwave radiation) and haline term (evaporation and precipitation) were calculated using the same method described previously and are shown in Table 3 (columns to the right of each parent term in boldface). The collocation of buoyancy flux maxima with wind speed maxima (Figs. 2 and 3) suggests that the turbulent heat fluxes may be strong drivers of the overall buoyancy loss. The relative contribution $(65 \%-75 \%)$ of the two turbulent fluxes to the thermal term confirms that turbulent fluxes dominate the overall buoyancy loss. The relative contribution of the LHF is similar $(46 \%-52 \%)$ for all patterns and makes a larger contribution to the buoyancy flux than the SHF. The SHF contribution is largest for patterns with northerly, barrier flow $(39 \%-40 \%)$, and it is slightly lower for patterns with weak barrier flow or southerly flow $(33 \%-35 \%)$. Like the turbulent fluxes, the net 


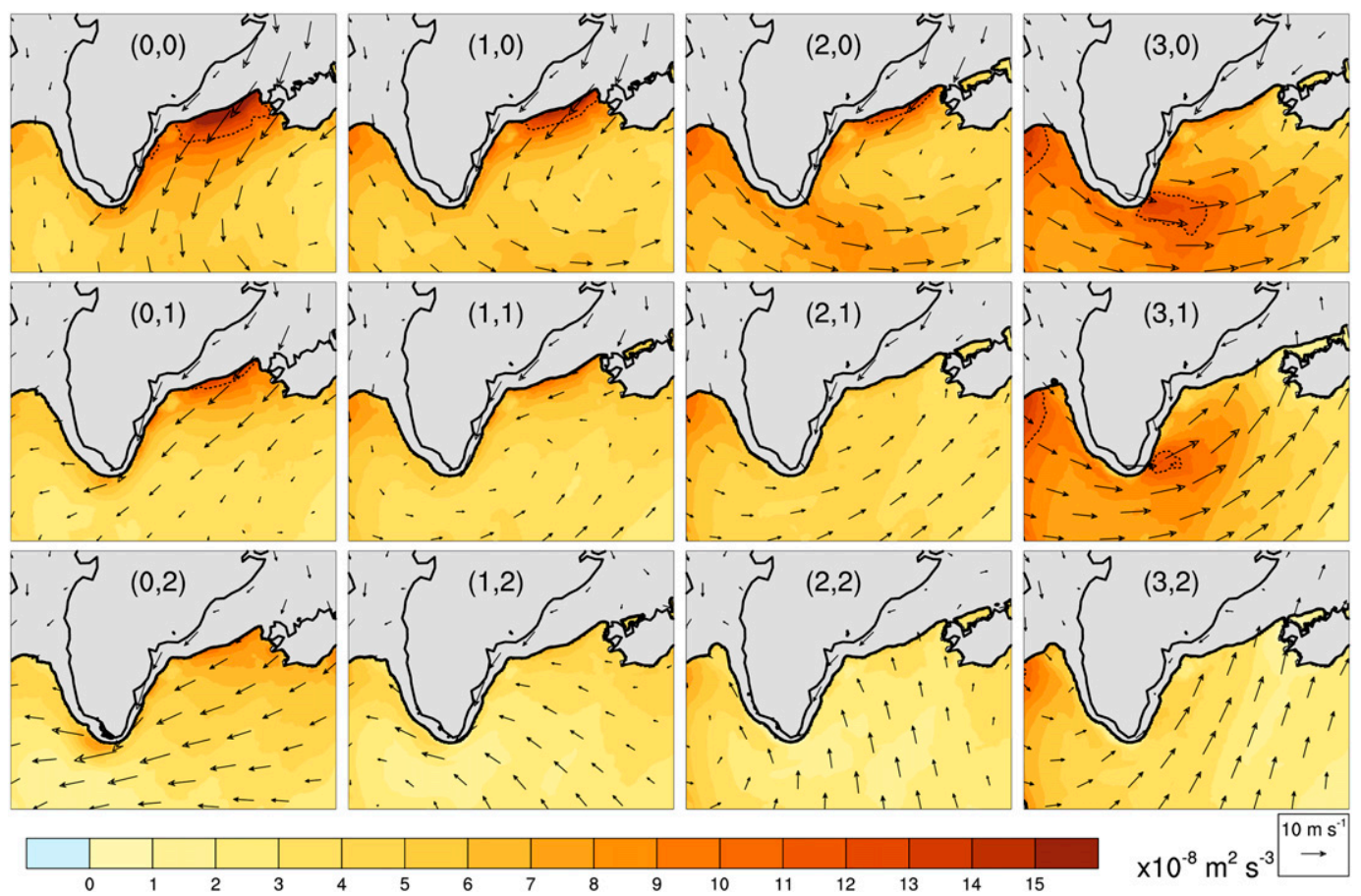

FIG. 3. RASM composite buoyancy flux $\left(\mathrm{m}^{2} \mathrm{~s}^{-3}\right)$ for each of the 12 representative wintertime (NDJFM) wind patterns identified by the SOM for 1990-2010. The dashed black contour shows the $11 \times 10^{-8} \mathrm{~m}^{2} \mathrm{~s}^{-3}$ buoyancy flux. The wind vectors are included to remind readers of the representative wind field, and the dark black contour represents the average $15 \%$ sea ice contour modeled by CICE in RASM for each pattern.

longwave flux also removes buoyancy from the ocean for all patterns, and it is more important for patterns with weak barrier flow or southerly flow $(33 \%-35 \%)$ than for patterns with northerly flow $(26 \%-27 \%)$. For all patterns, the net shortwave flux adds buoyancy to the ocean (from $-27 \%$ to $-11 \%$ ) and it is unsurprisingly small given the short winter daylight hours.

\section{b. Spatial patterns of buoyancy flux}

In this section, we investigate the spatial buoyancy flux fields in order to understand how the individual fluxes contribute to the net buoyancy loss. We have chosen to discuss the four corner patterns (Fig. 2) because they differ the most from one another and provide a sense of the ocean response to the range of wind events. To keep the focus on the four edge patterns and the dominant terms of the buoyancy flux (SHF, LHF, and longwave fluxes), Fig. 4 shows composites of the winds, buoyancy flux terms, and their contributing factors for the four corner patterns only. Because nearsurface atmospheric temperature and moisture are crucial components of the SHF and LHF, respectively, we have calculated the composite mean atmospheric temperature and moisture anomaly, which are found for each day using the 20 -yr daily mean values to remove the seasonal signal. Figures showing the contributions for each pattern in the 12 member SOM can be found in the supplementary material for various buoyancy flux terms (Figs. S1-S8) and the atmospheric temperature (Fig. S9) and moisture (Fig. S10) anomalies.

The composite wind speed for the four patterns is shown in Fig. 4a. These four corner patterns have also been identified in Moore (2014) as subgroups of tip jets. Pattern $(0,0)$ represents a northeasterly tip jet with barrier flow (NETJ) where the maximum wind speed occurs along the ice edge south of the Denmark Strait. Pattern $(0,2)$ represents an easterly tip jet with weaker barrier flow (ETJ) and maximum wind speed west of Cape Farewell. Pattern $(3,0)$ is a northwesterly tip jet with barrier flow (NWTJ) and maximum wind speed over the Irminger Sea to the east of Cape Farewell. Pattern $(3,2)$ has a southwesterly tip jet (SWTJ) with maximum speeds over the Irminger Sea northeast of Cape Farewell, but with a smaller magnitude maximum than the other corner patterns.

The thermal term (Fig. 4b) spatially resembles the wind speed (Fig. 4a) for patterns with northerly flow (NETJ and NWTJ) but not for patterns with a southerly component to the flow (ETJ and SWTJ). For the NETJ, the maximum thermal buoyancy loss occurs along the sea ice edge south of the Denmark Strait and decreases with distance from the ice edge. There is a secondary 
TABLE 3. Columns in boldface indicate the percent contribution of the thermal and haline terms to the net buoyancy flux for each SOM pattern; the haline term is three orders of magnitude smaller than the thermal term. The percent contributions of the latent heat flux, sensible heat flux, net longwave, and net shortwave terms to the thermal term are shown to the right of the thermal-term column. The percent contributions of the evaporation and precipitation terms to the haline term are shown to the right of the haline-term column. Blank rows in the table represent the row divisions for the SOM.

\begin{tabular}{|c|c|c|c|c|c|c|c|c|}
\hline Pattern & $\begin{array}{c}\text { Thermal } \\
\text { term }\end{array}$ & $\begin{array}{c}\text { Latent } \\
\text { heat } \\
\text { flux term }\end{array}$ & $\begin{array}{c}\text { Sensible } \\
\text { heat } \\
\text { flux term }\end{array}$ & $\begin{array}{l}\text { Net Long } \\
\text { wave term }\end{array}$ & $\begin{array}{l}\text { Net Short } \\
\text { wave term }\end{array}$ & Haline term & $\begin{array}{c}\text { Evaporation } \\
\text { term }\end{array}$ & $\begin{array}{c}\text { Precipitation } \\
\text { term }\end{array}$ \\
\hline 0,0 & $100 \%$ & $47.3 \%$ & $39.2 \%$ & $26.9 \%$ & $-13.4 \%$ & $1.5 \times 10^{-5} \%$ & $613.8 \%$ & $-513.8 \%$ \\
\hline 1,0 & $100 \%$ & $46.8 \%$ & $40.6 \%$ & $26.5 \%$ & $-13.9 \%$ & $1.0 \times 10^{-3} \%$ & $653.9 \%$ & $-553.9 \%$ \\
\hline 2,0 & $100 \%$ & $46.5 \%$ & $40.3 \%$ & $26.2 \%$ & $-13.0 \%$ & $2.0 \times 10^{-3} \%$ & $112.8 \%$ & $-12.8 \%$ \\
\hline 3,0 & $100 \%$ & $45.9 \%$ & $39.3 \%$ & $25.5 \%$ & $-10.7 \%$ & $1.9 \times 10^{-4} \%$ & $344.4 \%$ & $-244.4 \%$ \\
\hline 0,1 & $100 \%$ & $51.4 \%$ & $40.9 \%$ & $34.2 \%$ & $-26.5 \%$ & $3.7 \times 10^{-3} \%$ & $-155.3 \%$ & $255.3 \%$ \\
\hline 1,1 & $100 \%$ & $47.1 \%$ & $40.1 \%$ & $30.1 \%$ & $-17.3 \%$ & $7.1 \times 10^{-3} \%$ & $-292.0 \%$ & $392.0 \%$ \\
\hline 2,1 & $100 \%$ & $46.9 \%$ & $30.1 \%$ & $30.3 \%$ & $-17.2 \%$ & $8.0 \times 10^{-3} \%$ & $-149.6 \%$ & $249.6 \%$ \\
\hline 3,1 & $100 \%$ & $47.5 \%$ & $37.9 \%$ & $29.3 \%$ & $-14.8 \%$ & $1.5 \times 10^{-2} \%$ & $-852.8 \%$ & $952.8 \%$ \\
\hline 0,2 & $100 \%$ & $51.9 \%$ & $37.9 \%$ & $32.9 \%$ & $-22.7 \%$ & $4.4 \times 10^{-2} \%$ & $61.8 \%$ & $38.2 \%$ \\
\hline 1,2 & $100 \%$ & $49.9 \%$ & $37.4 \%$ & $34.8 \%$ & $-22.2 \%$ & $3.1 \times 10^{-2} \%$ & $68.7 \%$ & $31.3 \%$ \\
\hline 2,2 & $100 \%$ & $46.4 \%$ & $37.4 \%$ & $34.5 \%$ & $-18.2 \%$ & $3.5 \times 10^{-2} \%$ & $144.5 \%$ & $-44.5 \%$ \\
\hline 3,2 & $100 \%$ & $46.6 \%$ & $39.0 \%$ & $34.3 \%$ & $-19.9 \%$ & $1.6 \times 10^{-2} \%$ & $243.3 \%$ & $-143.3 \%$ \\
\hline
\end{tabular}

maximum along the coast and to the northeast of Cape Farewell. Both of these flux maxima coincide with wind speed maxima. Both the NETJ and ETJ have a local maximum for the thermal term just west of Cape Farewell, but only the ETJ has a maximum in wind speed collocated with this region of enhanced buoyancy flux. Like the NETJ, the ETJ has enhanced buoyancy loss along the sea ice edge but the ETJ has relatively weak winds in this location. The NWTJ has a local maximum in the thermal term over the Irminger Sea, where the largest wind speeds occur, but there is also a local maximum over the Labrador Sea where weaker winds are present. The buoyancy loss for the SWTJ is generally smaller than for the other patterns, other than in the Labrador Sea. For this pattern the largest buoyancy loss is not collocated with the largest wind speeds. Because the turbulent fluxes are the largest contributors to buoyancy loss (Table 3) and because they depend directly on wind speed, the similarity between the wind speed and flux field is not surprising. However, because each pattern has regions of elevated buoyancy loss where there are weak winds, it is necessary to examine temperature and moisture influences on the turbulent fluxes.

The SHF (Fig. 4c) for all patterns is elevated along the sea ice edge - south of the Denmark Strait for NETJ and ETJ and in the Labrador Sea for the NWTJ and SWTJwhere anomalously cold atmospheric temperatures (Fig. 4d) first encounter the relatively warm ocean waters. The magnitude of buoyancy loss decreases with distance from the ice edge as the cold atmospheric temperature anomaly decreases and the atmosphere adjusts to the flux of heat from the ocean. For both the NETJ and ETJ, elevated SHFs south of the Denmark Strait decrease to the south as the cold temperature anomaly becomes weaker, but for the NETJ the decrease in fluxes corresponds to a decrease in wind speed, while the ETJ decrease in fluxes corresponds to an increase in wind speed. Both the NWTJ and SWTJ have local maximum in SHF in the Labrador Sea, where relatively weak westerly atmospheric flow brings cold air off the North American continent or sea ice over the open ocean (Renfrew and Moore 1999). For the NWTJ there is also elevated buoyancy loss due to the SHFs immediately east of Cape Farewell, where both a maximum in wind speed and a minimum in temperature anomaly exist. In all patterns the largest SHFs occur where there are anomalously cold atmospheric temperatures, so changes in the temperature anomaly drive changes in the SHF, while changes in wind speed are of secondary importance.

The LHFs over the open ocean (Fig. 4e) depend on both the atmospheric moisture anomaly (Fig. 4f) and the wind speeds (Fig. 4a). For NETJ, the largest LHF is along the sea ice edge where the driest northerly flow encounters the ocean surface and there is a wind speed maximum; however, along the coast to the northeast of Cape Farewell, the LHF is not elevated because the air is less anomalously dry even though the wind speeds are elevated. The ETJ has anomalously moist conditions in the vicinity of maximum wind speeds southwest of Cape Farewell, so the LHFs for this pattern are relatively weak. Similar to the NETJ, the maximum LHF for the NWTJ occurs where a maximum in wind speed and 
(a)

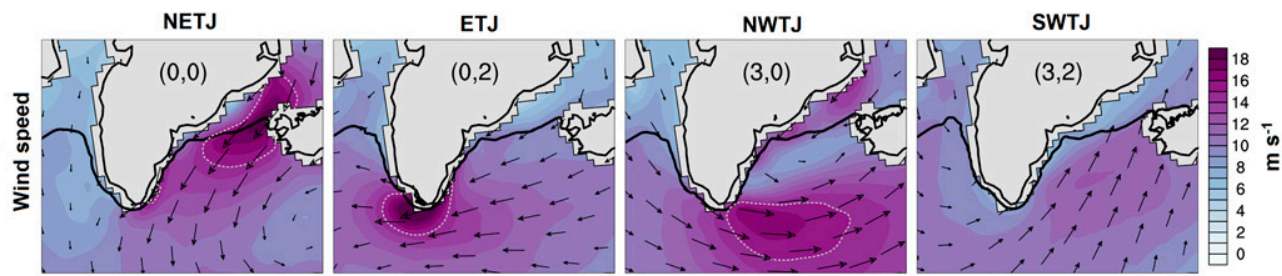

(b)

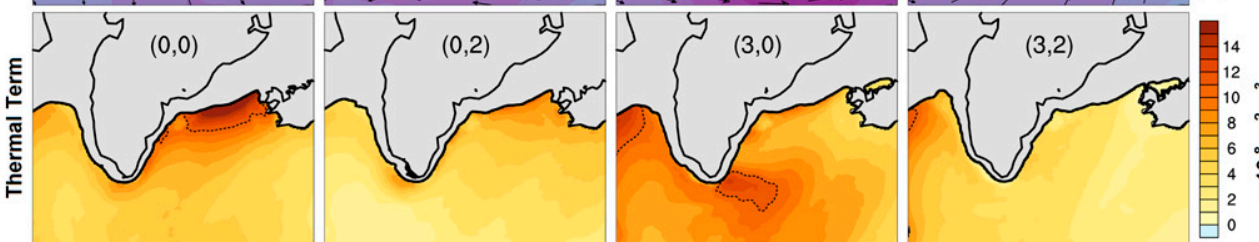

(c)

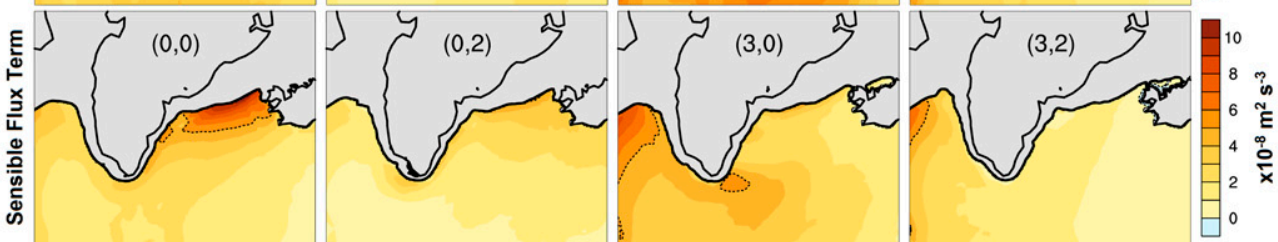

(d)
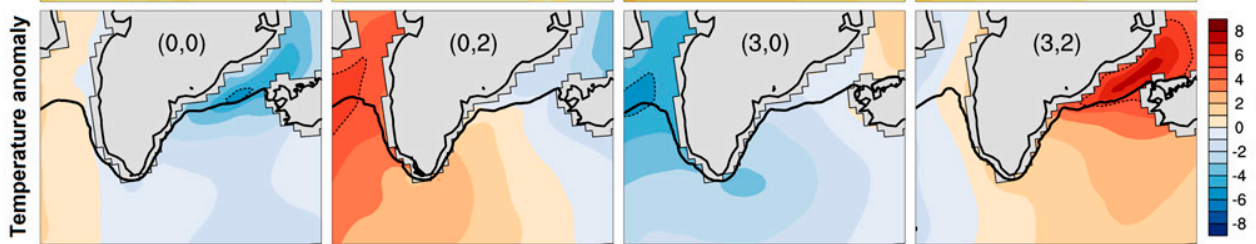

(e)

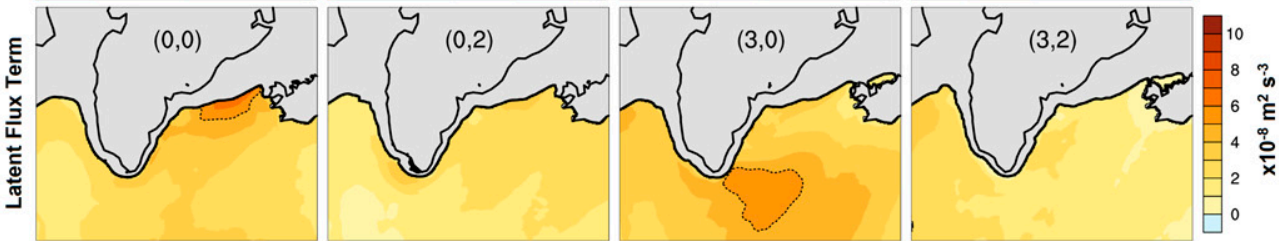

(f)

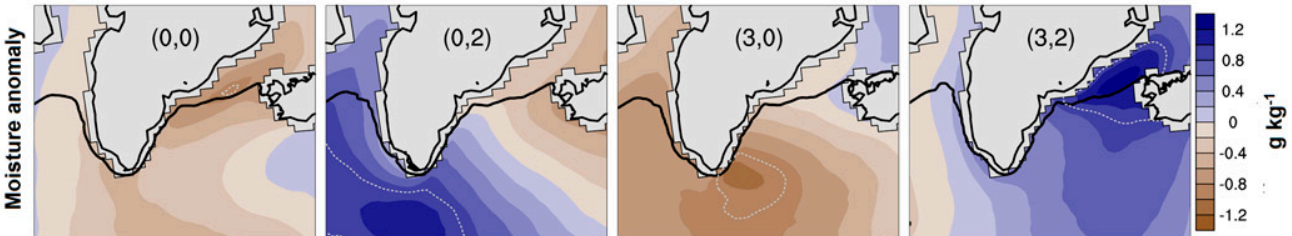

(g)

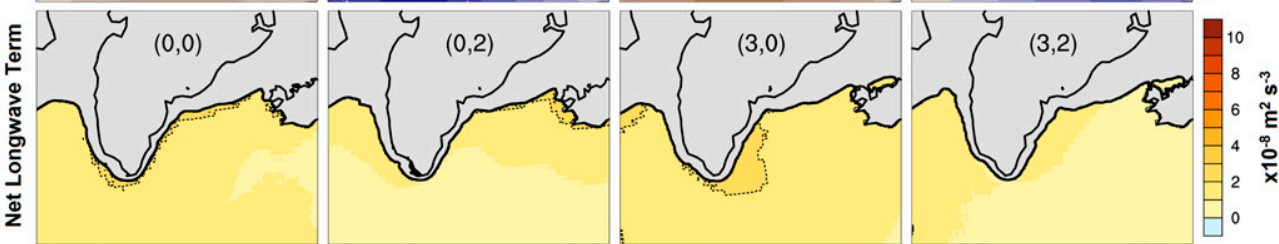

(h)

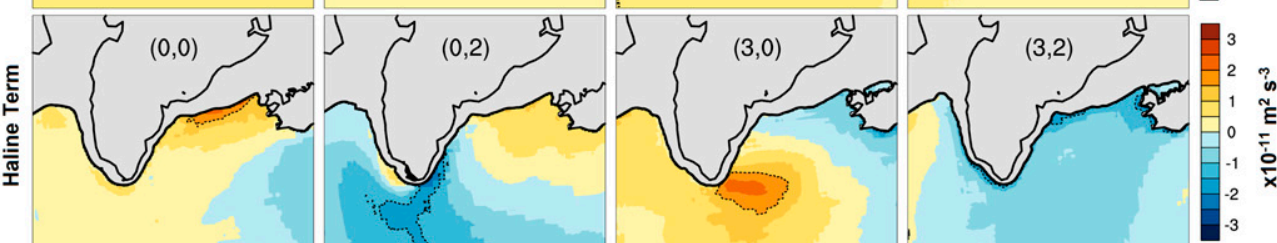

FIG. 4. (a) Composite wind speed $\left(\mathrm{m} \mathrm{s}^{-1}\right)$ and wind direction for the corner patterns: NETJ [pattern $\left.(0,0)\right]$, ETJ [pattern $(0,2)]$, NWTJ [pattern $(3,0)]$, and SWTJ [pattern $(3,2)]$. Composite (b) thermal buoyancy term $\left(\mathrm{m}^{2} \mathrm{~s}^{-3}\right)$, (c) sensible heat flux buoyancy term $\left(\mathrm{m}^{2} \mathrm{~s}^{-3}\right)$, (d) near-surface atmospheric temperature anomaly $\left({ }^{\circ} \mathrm{C}\right),(\mathrm{e})$ latent heat flux buoyancy term $\left(\mathrm{m}^{2} \mathrm{~s}^{-3}\right)$, (f) near-surface atmospheric moisture anomaly $\left(\mathrm{g} \mathrm{kg}^{-1}\right),(\mathrm{g})$ net longwave buoyancy term $\left(\mathrm{m}^{2} \mathrm{~s}^{-3}\right)$, and $(\mathrm{h})$ haline buoyancy term $\left(\mathrm{m}^{2} \mathrm{~s}^{-3}\right)$. The dashed contours show the following contour limits: $15 \mathrm{~m} \mathrm{~s}^{-1}$ in (a), $11 \times 10^{-8} \mathrm{~m}^{2} \mathrm{~s}^{-3}$ in (b), $5 \times 10^{-8} \mathrm{~m}^{2} \mathrm{~s}^{-3}$ in (c), $\pm 5^{\circ} \mathrm{C}$ in (d), $5 \times 10^{-8} \mathrm{~m}^{2} \mathrm{~s}^{-3}$ in (e), $\pm 0.9 \mathrm{~g} \mathrm{~kg}^{-1}$ in (f), $2 \times 10^{-8} \mathrm{~m}^{2} \mathrm{~s}^{-3}$ in (g), and $\pm 1.5 \times 10^{-11} \mathrm{~m}^{2} \mathrm{~s}^{-3}$ in (h). In all panels, the dark black contour represents the average $15 \%$ sea ice contour modeled by CICE in RASM for each pattern. 
anomalously dry air are collocated (i.e., southeast of Cape Farewell). However, in the Labrador Sea the LHFs are not elevated because weak winds are collocated with anomalously dry conditions. The SWTJ has anomalously moist conditions and low wind speeds that lead to smaller LHFs relative to other patterns. The combination of anomalously dry air and strong winds is important to generate a large LHF. Dry air but weak winds, such as over the Labrador Sea for NWTJ, or strong winds but moist air, such as west of Cape Farewell for ETJ, result in small LHFs.

Near the sea ice edge, the buoyancy loss from the SHF is largest, but over the ocean the magnitudes of buoyancy loss from SHF and LHF are similar. For all patterns, the ocean loses buoyancy from the SHF (LHF) over the entire domain because the temperature (moisture) gradient is such that the atmosphere is colder (drier) than the ocean surface. The temporal and spatial evolution of the magnitude of the temperature (moisture) gradient is driven primarily by the atmospheric temperature (moisture) anomaly rather than the sea surface conditions, which vary less relative to the atmospheric state. The combination of wind speed maxima and anomalously cold and dry conditions, and thus large temperature and moisture gradients between the ocean and atmosphere, leads to the largest turbulent fluxes and buoyancy loss from the ocean.

The net longwave flux (Fig. $4 \mathrm{~g}$ ) is smaller in magnitude than the turbulent fluxes and is fairly constant over the whole domain, indicating that the impact of wind patterns on cloud cover is small. Slightly elevated buoyancy loss can be seen for NWTJ to the east of Cape Farewell, where dry, off-continent flow would likely lead to clearer skies and more longwave loss from the ocean. The shortwave flux (Fig. S5) is fairly constant over the whole domain as well, though in areas with clear sky, like that for the NWTJ, the oceanic buoyancy gain is slightly larger.

Unlike the thermal buoyancy term, which in this case only acts to remove buoyancy from surface waters (Fig. 4b) by thermal energy loss that increases density of surface waters, the haline buoyancy term (Fig. 4h) both removes and adds buoyancy to surface waters. Precipitation uniformly adds buoyancy by adding freshwater to the ocean surface, which decreases density, while evaporation uniformly removes buoyancy by removing freshwater from surface water, which increases density. However, the overall impact of the haline term depends on the difference in evaporation and precipitation [Eq. (1)], so specifics of local precipitation and evaporation patterns are important for the overall impact of the haline term. In locations where there is upslope atmospheric flow onto the Greenland continent, such as for the ETJ and SWTJ patterns, localized precipitation can lead to a negative haline term and oceanic buoyancy gain (Fig. 4h). Yet the haline contribution to the total buoyancy term is still negligibly small compared to the thermal terms. (Note: the color bar for the haline buoyancy term in Fig. 4h is three orders of magnitude smaller than for the thermal buoyancy term in Fig. 4b.)

\section{Ocean response}

\section{a. Mixed layer depth changes}

The oceanic buoyancy loss that occurs for all wind patterns (Fig. 3) indicates that the surface waters are becoming denser. Profiling floats (Centurioni and Gould 2004) and moorings in the Irminger Sea [Fig. 5 from Våge et al. (2008) and Fig. 5 from De Jong et al. (2012)] indicate that throughout the winter season the MLD typically deepens to approximately $400 \mathrm{~m}$ in this basin and that the deepest MLD exceeds 800-m depth. Figure 5a shows the evolution of the MLD in RASM at the grid points nearest the locations of three moorings (shown on Fig. 5b) for the winter season 1990-2010. RASM is able to reproduce the seasonal deepening of MLDs, restratification episodes near the end of winter, and the interannual variability in maximum MLD seen in the observations. Typical modeled maximum MLD in RASM is approximately $400 \mathrm{~m}$ (see caption for Fig. 5a), which is consistent with observations, and the modeled MLD maxima in winter seasons 2007/08 and 2008/09 (Fig. 5a) are also consistent with the observations (De Jong et al. 2012, their Fig. 5).

In the southwestern Irminger Sea, RASM simulates average seasonal maximum MLD of $400-500 \mathrm{~m}$ (Fig. 5b), and the deepest MLD simulated over all 20 winter seasons exceeds $800 \mathrm{~m}$ (Fig. 5c). These values are consistent with observations showing years when the deepest MLD exceeds $800 \mathrm{~m}$ (De Jong et al. 2012) in this region. In the northeastern Irminger Sea, near the sea ice edge and Icelandic continental shelf, RASM results show a deeper average maximum MLD of about $1000 \mathrm{~m}$ (Fig. 5b), and the deepest simulated MLD over 20 winter seasons in the northeastern Irminger Sea exceeds $1500 \mathrm{~m}$ (Fig. 5c). While the authors are unaware of MLD measurements from moorings in this region, float profile observations of the region from 1994 to 2003 presented by Centurioni and Gould (2004) suggest that the northeastern Irminger basin does not have particularly favorable conditions for convection, and a single Argo float observed mixed layer depths around $600 \mathrm{~m}$ in the northeastern Irminger basin during the winter of 2007/08 (Våge et al. 2008). Therefore, in the northeastern Irminger Sea, the modeled MLD does not match the 

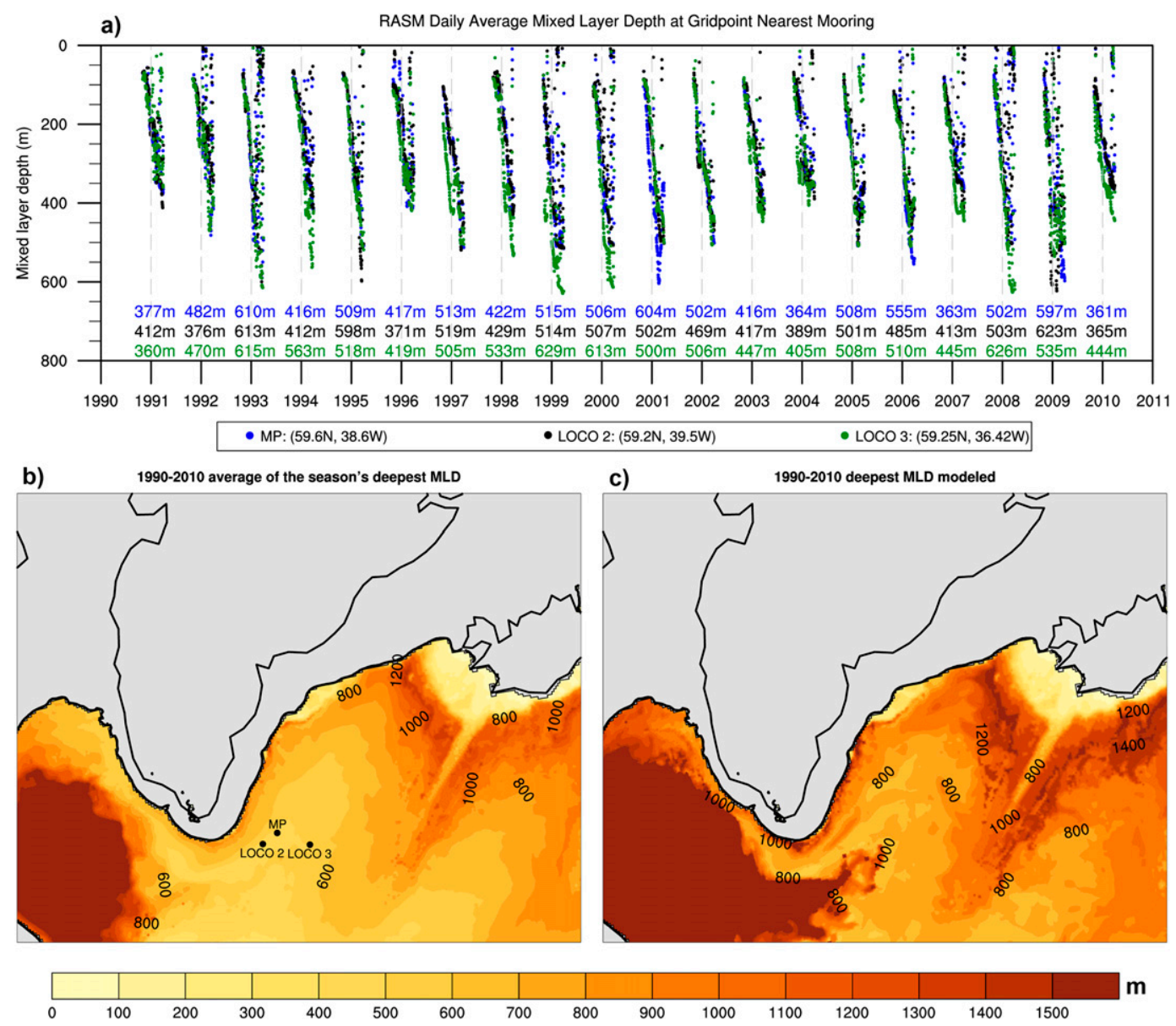

FIG. 5. The (a) 1990-2010 daily average MLD from 1 Nov to 31 Mar at the RASM grid points nearest MP (blue), LOCO 2 (black), and LOCO 3 (green) observations mentioned in text. Year labels mark 1 Jan of that year, and the deepest MLD modeled for each season at each point is listed below that season's MLD time series. (b) The average of the season's deepest MLD modeled at each point for 1990-2010 and locations of the MP, LOCO 2, and LOCO 3 observations. (c) The absolute deepest MLD modeled at each point for 1990-2010. The dark black contour in (b),(c) represents the average 15\% sea ice contour modeled by CICE for 31 Mar 1990-2010.

scant observations well, but this appears to be confined to this particular section of the Irminger Sea basin because the mooring observations match the model well elsewhere in the basin. The average maximum MLD (Fig. 5b) and absolute deepest MLD (Fig. 5c) is deeper in the Labrador Sea than the Irminger Sea, which is consistent with observations showing frequent MLDs deeper than $2000 \mathrm{~m}$ in the Labrador Sea (Lazier et al. 2002).

As seen in Fig. 5a, the MLD deepens over the winter, but there are also periodic restratification events [e.g., mooring location Long-Term Ocean Climate Observations (LOCO) 3 in 1997] as well as days with enhanced deepening [e.g., mooring point (MP) location in 2001]. To understand how the MLD changes after different types of wind events, Fig. 6 shows the composite average of the change in MLDs one day after each of the wind patterns. In the Irminger Sea, a widespread deepening of the MLDs of $10-30 \mathrm{~m}$ follows wind events with northerly flow (Fig. 6, top row). This deepening occurs both in locations with very large buoyancy loss, such as along the sea ice edge in pattern $(0,0)$ or to the southeast of Cape Farewell for patterns $(2,0)$ and $(3,0)$, but also in locations with smaller buoyancy loss. Similarly, in the Labrador Sea deepening occurs after wind patterns with strong buoyancy loss-patterns $(3,0),(3$, $1)$, and $(3,2)$ - but also after patterns with weaker buoyancy loss, such as patterns $(1,2)$ and $(2,2)$. For wind events with southerly flow, there is shoaling of the MLDs over most of the Irminger Sea for pattern $(1,2)$, while patterns $(2,2)$ and $(3,2)$ result in a mix of deepening and shoaling (Fig. 6). The large magnitude $(>|100| \mathrm{m})$ changes in MLDs southwest of Iceland (i.e., the "whale tail" on Fig. 6) follow the ocean bathymetry 


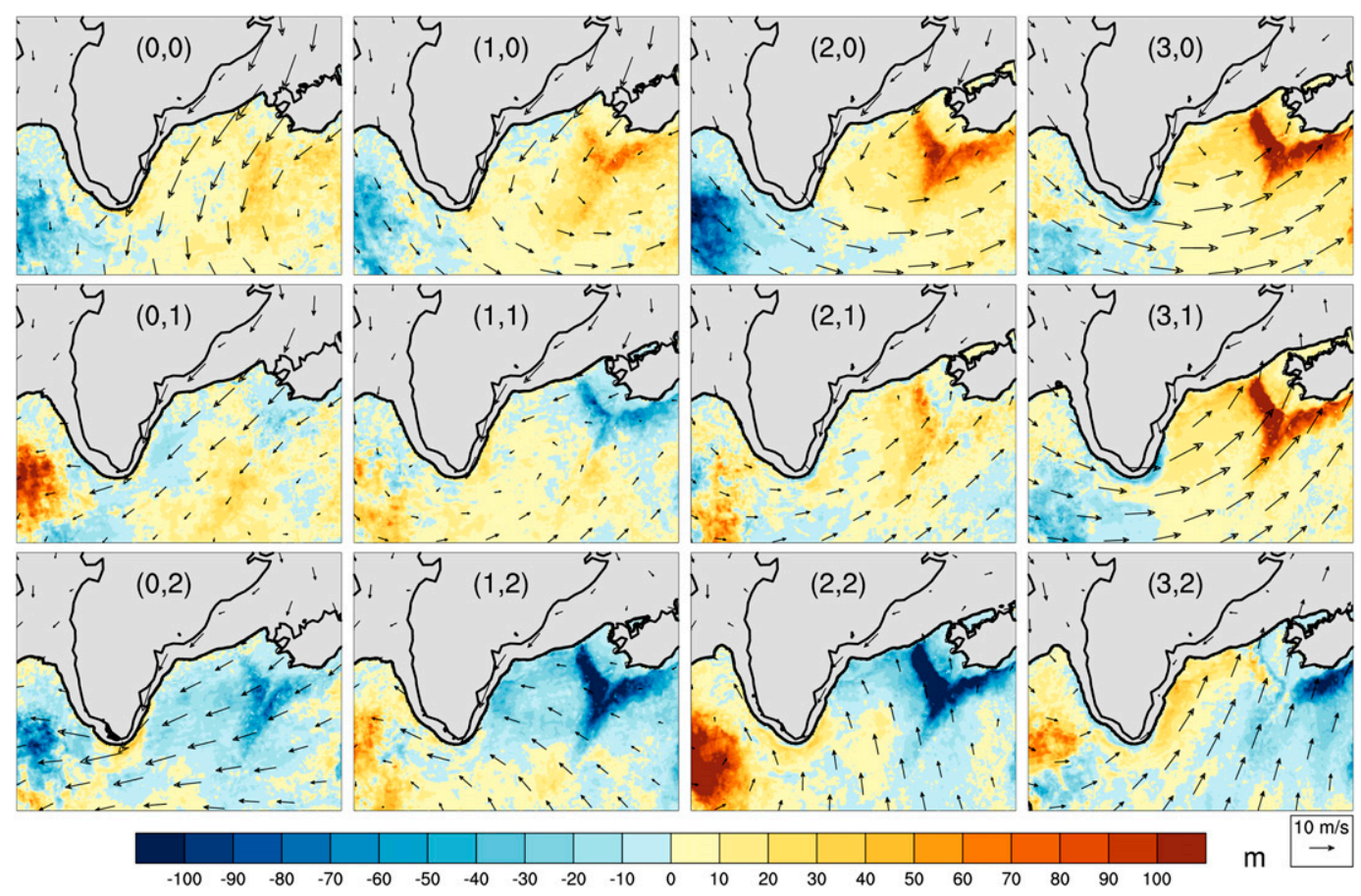

FIG. 6. RASM composite change in MLD (m) one day following a wind event for each of the 12 representative wintertime (NDJFM) wind patterns identified by the SOM for 1990-2010. Reds (blues) indicate deepening (shoaling) of the MLD. The wind vectors are included to remind readers of the representative wind field, and the dark black contour represents the average $15 \%$ sea ice contour modeled by CICE in RASM for each pattern.

(Fig. 1b) and do not correspond to locations of large buoyancy loss.

While there is buoyancy loss for all wind patterns (Fig. 3), MLD evolution is a complex process (e.g., McGeehan and Maslowski 2011), and simply assessing buoyancy flux maxima or minima for particular patterns is not sufficient to fully explain the MLD changes following a wind event, as seen in Fig. 6. Similar magnitude deepening can occur in locations of large or small buoyancy loss, and MLD shoaling also occurs in locations with relatively small buoyancy loss. In locations with a weak buoyancy flux, deepening may be the result of preconditioning from previous events so that a smaller flux may be sufficient to cause deepening. Particularly in the presence of relatively weak buoyancy forcing, MLD changes may also be driven by other processes, such as mechanical atmospheric forcing (surface mixing, Ekman pumping, etc.) or air-sea iceocean interactions (McGeehan and Maslowski 2011), which are not analyzed here.

As discussed in section $3 \mathrm{a}$, the buoyancy flux is dominated by the turbulent SHF and LHF. These turbulent fluxes depend on both wind stress, which is a mechanical forcing, and temperature or moisture gradients, which are thermodynamic forcing. To understand how changes in MLD depend on the mechanical portion or the thermodynamic portion of the buoyancy flux, we have correlated the change in MLD one day after an event with the wind stress, the temperature gradient, and the moisture gradient on the day of the event. For northerly flow patterns, where we see widespread MLD deepening, the wind stress and both gradient terms are positively correlated with the change in MLD in the regions with the largest buoyancy flux (not shown). This indicates that the MLD deepens more when there is a greater surface stress or larger gradients. However, the magnitude of the correlation is greater and a larger area is significant for both gradient terms than for the surface stress. Therefore, the thermodynamic rather than the mechanical component of the turbulent fluxes dominates the change in MLD.

\section{b. Long-versus short-duration events}

Because the ocean has a relatively long memory compared to the atmosphere, longer-duration strong wind events are expected to impact the ocean more than short-duration events. We define the start of an event if the previous day mapped to a different wind pattern in the SOM. The duration of an event is the number of sequential days that map to the same wind pattern. We define short events as those that last one day only and long events as those that last three or more days. Table 4 
TABLE 4. Frequency of events of different duration for each SOM pattern. An event is defined as beginning when the previous day's pattern did not map to the same pattern. The duration is the number of sequential days that map to the same pattern. Blank rows in the table represent the row divisions for the SOM.

\begin{tabular}{cccr}
\hline \hline Pattern & 1 day & 2 days & $3+$ days \\
\hline 0,0 & $52.2 \%$ & $27.3 \%$ & $19.4 \%$ \\
1,0 & $69.2 \%$ & $21.4 \%$ & $9.3 \%$ \\
2,0 & $74.3 \%$ & $17.4 \%$ & $8.3 \%$ \\
3,0 & $69.8 \%$ & $22.0 \%$ & $8.2 \%$ \\
0,1 & & & \\
1,1 & $79.8 \%$ & $15.5 \%$ & $4.7 \%$ \\
2,1 & $86.6 \%$ & $12.3 \%$ & $1.1 \%$ \\
3,1 & $86.6 \%$ & $12.6 \%$ & $0.8 \%$ \\
0,2 & $59.8 \%$ & $30.5 \%$ & $9.8 \%$ \\
1,2 & & & \\
2,2 & $52.8 \%$ & $19.0 \%$ & $28.2 \%$ \\
3,2 & $80.0 \%$ & $16.5 \%$ & $3.5 \%$ \\
\hline
\end{tabular}

gives the percent of time that each wind pattern lasts for one day, two days, and three or more days. For all patterns, most events last a single day $(\sim 71 \%)$, while a smaller percentage last three or more days $(\sim 10 \%)$. For this discussion, we will focus on the NETJ and NWTJ patterns-patterns $(0,0)$ and $(3,0)$, respectively-since we have shown that these patterns have the largest buoyancy forcing and most widespread deepening of the MLD.

Figures $7 \mathrm{a}$ and $7 \mathrm{~b}$ show the wind speed and total buoyancy flux for the first day of the average short and long NETJ and NWTJ event, and the corresponding change in oceanic MLD over that first day. On the first day of a new event there are faster wind speeds and larger buoyancy fluxes out of the ocean for long events compared to short events, which suggests that long events have stronger background forcing than short events. For NETJ (Fig. 7a), in the Irminger Sea there is similar magnitude deepening for long and short events, but the long events result in deepening over a larger area. In the Irminger Sea, the spatial pattern and magnitude of MLD change is similar for both the short and long NWTJ events (Fig. 7b). The relatively similar MLD response in the Irminger Sea to the differing strength of buoyancy forcing for long and short events indicates that after one day the ocean is not responding differently to the stronger forcing associated with long-duration events. In the Labrador Sea, the long NWTJ results in more deepening compared to the short NWTJ, which is consistent with the larger buoyancy flux in this region for long NWTJ.

The difference in ocean MLD response to short and long events and the importance of the long ocean memory is more apparent when we investigate several days after the start of an event. Three days after an event begins a long event is just ending while a short event is over, and the winds have transitioned to a different wind pattern. For both short and long NETJ and NWTJ events, after three days the average wind speeds (Figs. 7c,d) are weaker than on the first day of an event (Figs. 7a,b). However, the repetition of the wind field over all three days causes the average wind speeds for long events to be more similar to the first day of an event. For long events, the three-day average buoyancy flux (Figs. 7c,d) is slightly reduced in magnitude, though otherwise similar to the buoyancy flux on the first day of an event (Fig. 7a,b). However, for short events the threeday average buoyancy flux is weaker because the wind pattern has transitioned, and the original buoyancy signal is diluted as a result of averaging with the buoyancy signals associated with the new wind patterns. Three days after the start of an NETJ (Fig. 7c), long events have a larger area of MLD deepening along the sea ice edge south of the Denmark Strait and north of Cape Farewell along Greenland's southeastern coast when compared to short events, and these areas are collocated with larger three-day average buoyancy fluxes for long events. There is greater magnitude MLD deepening that occurs over a larger area in the Labrador and Irminger Seas for long NWTJ compared to short NWTJ (Fig. 7d), and the regions with increased MLD deepening correspond to larger three-day average buoyancy fluxes.

\section{c. Interannual variability}

Because RASM is able to reasonably simulate observed MLDs over a sequence of years (Fig. 5a), we explore how interannual variability in the different wind pattern frequencies impacts the seasonally deepest MLD by correlating the yearly frequency of each atmospheric pattern with each season's deepest MLD at each point. A positive (negative) correlation indicates when the pattern occurs more frequently that year's maximum MLD is deeper (shallower). Correlations are assumed to be linear with no lag, and significance of the correlation coefficient was calculated using the $r$ test. Note that, over much of the Icelandic continental shelf, the maximum MLD is equal to the depth of the continental shelf for all 20 winters, so a correlation coefficient is not meaningful, and this region has been shaded white in Fig. 8.

Patterns with strong westerly winds in the Irminger Sea-patterns $(2,0),(3,0)$, and $(3,1)$-have large regions of positive and statistically significant correlation between pattern frequency and maximum MLD in both the Irminger and Labrador Seas (Fig. 8). For these patterns, the greatest correlation occurs where there are 
(a) NETJ - 1 day

(b) NWTJ - 1 day

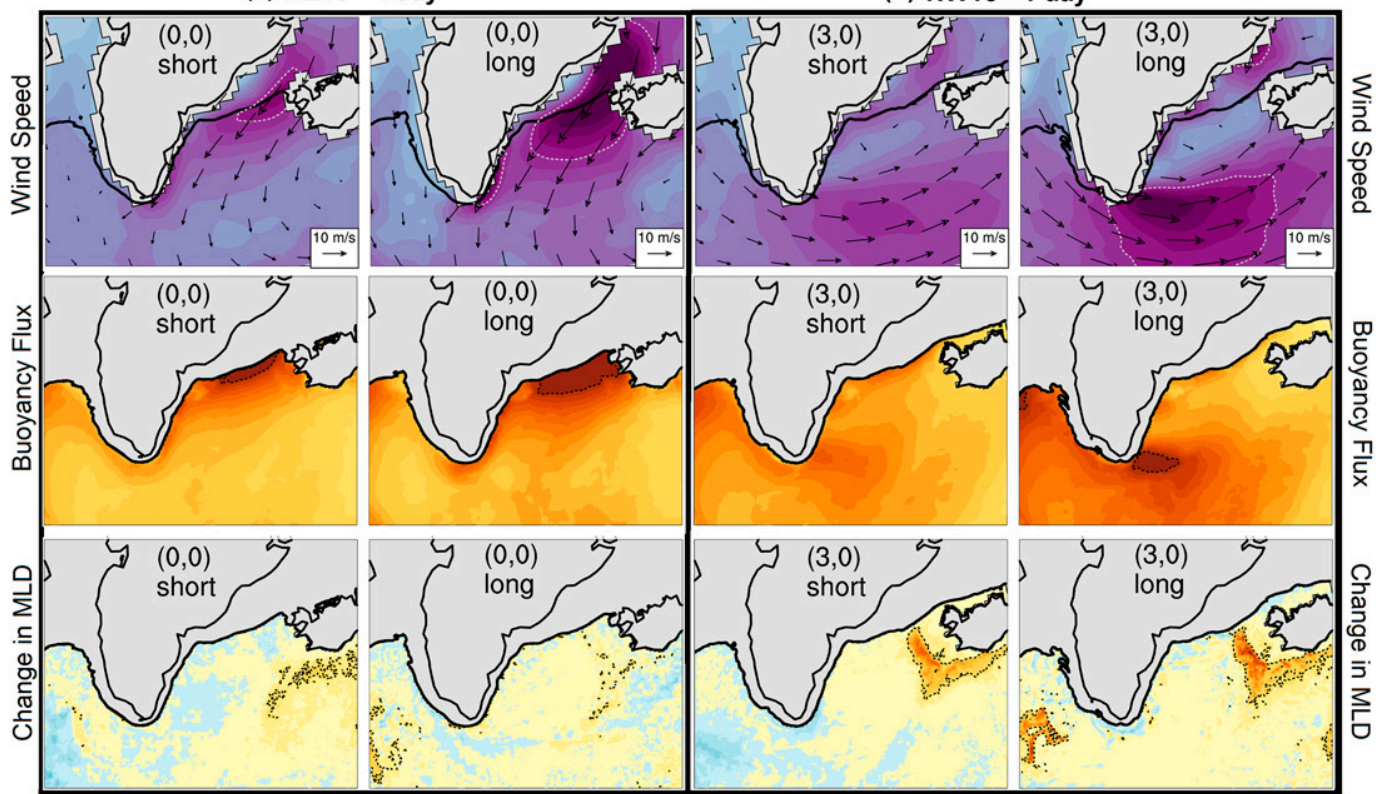

(c) NETJ - 3 days

(d) NWTJ - 3 days

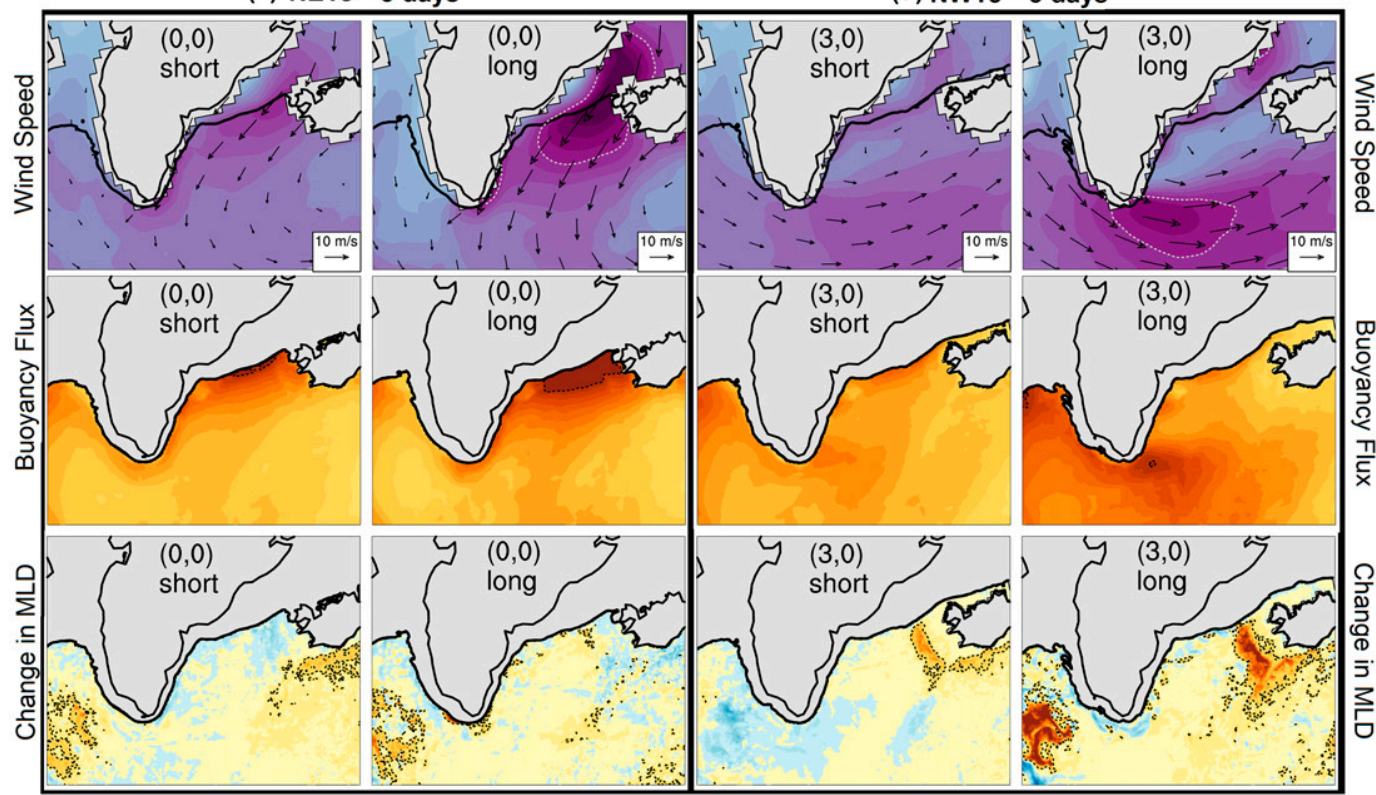

Wind

Speed

Buoyancy

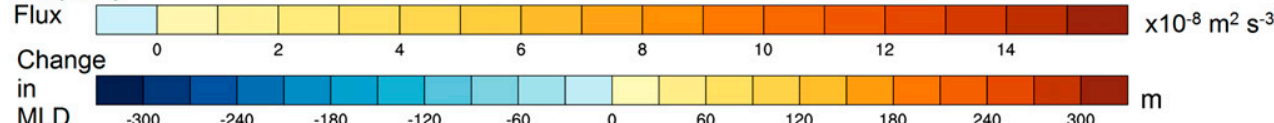

FIG. 7. Composite of short- and long-duration in the left and right columns of each panel, respectively, for (a),(c) NETJ [pattern $(0,0)$ ] and (b),(d) NWTJ [pattern $(3,0)$ ] events. (top) Composite wind speed $\left(\mathrm{m} \mathrm{s}^{-1}\right)$, (middle) net buoyancy flux $\left(\mathrm{m}^{2} \mathrm{~s}^{-3}\right)$, and (bottom) change in MLD $(\mathrm{m})$ in the top, middle, and bottom rows of each panel, respectively, over the first day of an event in (a),(b) or over the first three days of an event in (c),(d). The dashed contours show the following contour limits in the subpanels: $15 \mathrm{~m} \mathrm{~s}^{-1}$ for wind speed, $15 \times 10^{-8} \mathrm{~m}^{2} \mathrm{~s}^{-3}$ for buoyancy flux, and 75-m change in MLD. The dark black contour represents the average $15 \%$ sea ice contour predicted by CICE in RASM for each pattern. 


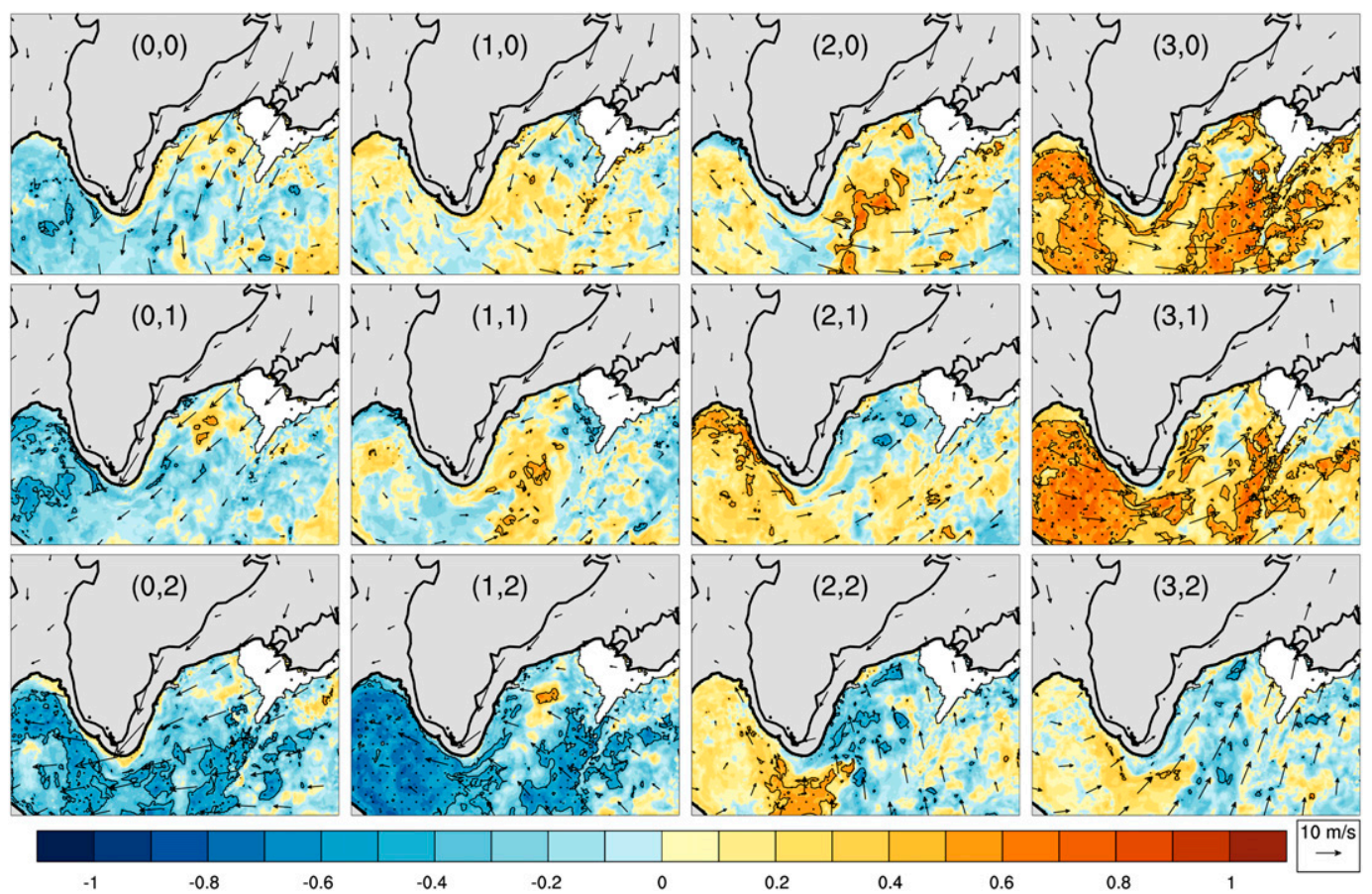

FIG. 8. Correlation between pattern frequency and the season's deepest MLD over 20 winter seasons for each of the 12 representative wintertime (NDJFM) wind patterns identified by the SOM for 1990-2010. Correlations that are significant at the $95 \%$ level are stippled, and white shaded areas indicate locations where the correlation is undefined because the seasonal deepest MLD is the same all 20 seasons. Wind vectors are included to remind readers of the representative wind field, and the dark black contour represents the average $15 \%$ sea ice contour predicted by CICE in RASM for each pattern.

large buoyancy fluxes in the Irminger and Labrador Seas (Fig. 3). Conversely, patterns $(0,2)$ and $(1,2)$ have a predominantly negative and significant correlation over both the Labrador and Irminger Seas (Fig. 8) where the associated buoyancy flux is small (Fig. 3). In general, patterns that have northerly flow and strong buoyancy loss near the sea ice edge (Fig. 3, top row) have a positive correlation in the regions collocated with the large buoyancy fluxes (Fig. 8). Thus, when patterns with northerly flow occur more often, deeper maximum MLDs occur off the ice edge and are likely due to the large buoyancy loss in that area. Patterns with westerly flow and elevated buoyancy loss over the Labrador Sea (Fig. 3, right column) have a positive correlation with maximum MLD over the Labrador Sea (Fig. 8). Conversely, patterns with a component of easterly flow over the Labrador Sea (Fig. 3, left column) have small buoyancy loss and are negatively correlated with the season's deepest MLD (Fig. 8). Curiously, patterns $(1,1)$ and $(2,2)$ have areas of positive, significant correlation in the southern Irminger Sea (Fig. 8) that are not collocated with buoyancy loss and may reflect other processes (e.g., oceanic advection and eddy transport) driving the MLD deepening.
The relationships between pattern frequency and the season's deepest MLDs in both the Labrador and Irminger Seas are consistent with the buoyancy forcing and temperature anomalies discussed in section $3 \mathrm{a}$. In general, northerly flow over the Irminger Sea or westerly flow over the Labrador Sea advects cold air over the open water and drives large buoyancy loss, and when a wind pattern in which this occurs happens more frequently, there are more likely to be deeper maximum MLDs that season in locations of large buoyancy loss. The deepest MLDs across the Labrador and Irminger Seas occur when patterns $(3,0)$ and $(3,1)$ are frequent, because they drive cold northerly winds over part of the Irminger Sea and westerly winds over the Labrador Sea and southern Irminger Sea. The season's deepest MLDs will be shallower when patterns $(0,2)$ and $(1,2)$ occur frequently, because they bring warmer, southeasterly winds over the Labrador and Irminger Seas.

\section{Discussion and conclusions}

The ocean loses buoyancy and becomes denser during all types of wintertime wind patterns that occur around 
southeastern Greenland (Fig. 3). This buoyancy loss is primarily driven by the thermal term, while the haline contribution to the buoyancy flux is negligible (Table 3). This might be explained by the fact that the winter average sea surface temperature in the Irminger Sea is relatively warm (at $+5.5^{\circ} \mathrm{C}$ modeled by RASM; not shown) and subject to a large temperature change due to atmospheric cooling. In addition, the positive haline contribution to the surface buoyancy flux is diminished by the cooling effect of precipitation in high latitudes, especially in winter. Using estimates of precipitation and evaporation over the Atlantic, Schmitt et al. (1989) also found that at high latitudes the thermal density flux dominates over the haline density flux. They attribute the small haline contribution to density loss to a reduced magnitude hydrologic cycle at high latitudes due to relatively dry conditions as a result of cold atmospheric temperatures. However, the contribution of the haline term to buoyancy loss in the subpolar North Atlantic could vary spatially based on sea surface temperature. For example, Moore et al. (2002), using reanalysis data in the Weddell Sea, and Sathiyamoorthy and Moore (2002), using observations in the Labrador Sea, find that freshwater flux, particularly from precipitation, is a crucial component to open water buoyancy flux. They attribute it to the nonlinearity of the equation of state for seawater: the thermal expansion coefficient $\alpha_{T}$ depends strongly on temperature, while the saline contraction coefficient $\beta$ is less sensitive, so at cold temperatures $\left(\sim+3^{\circ} \mathrm{C}\right.$ in the Labrador Sea as modeled by RASM, not shown) the thermal contribution diminishes while the saline contribution increases. For calculating the buoyancy flux [Eq. (1)] using POP output, we have assumed the thermal and haline expansion coefficients at constant values (Table 2) that are appropriate for this region. However, this approach may reduce the importance of the haline term because of the nonlinearity of these terms and variation in sea surface temperature in this region. Finally, the haline component could be further underrepresented in this study if the RASM atmosphere simulates too little precipitation in this region. Further evaluation of RASM's simulated precipitation over the Arctic system, including the Irminger basin, is underway but beyond the scope of the present study.

The thermal buoyancy terms dominate buoyancy loss (Table 3), and of these the longwave radiative contribution to buoyancy loss $(25 \%-35 \%)$ is less than the turbulent heat flux terms $(65 \%-75 \%)$, while net shortwave radiation adds a small amount of buoyancy to the surface waters. The turbulent flux contributions to the buoyancy loss tend to have similar patterns to the wind field and atmospheric temperature and moisture anomalies, while the radiation contributions are relatively uniform throughout the domain and do not differ considerably for the different wind patterns. Patterns with the largest buoyancy fluxes have northerly or westerly flow that brings cold, dry air over the ocean, while patterns with southerly flow tend to have warmer, moister air that results in a smaller buoyancy loss (Figs. 3 and 4). In regions where cold atmospheric temperature anomalies (Fig. 4d) occur over the relatively warmer ocean, SHF (Fig. 4c) causes a large buoyancy loss, which is enhanced when strong winds are collocated with the anomalously cold air (Fig. 4a). For LHF loss (Fig. 4e), however, the combination of dry atmospheric conditions (Fig. 4f) and fast winds (Fig. 4a) is important to drive the largest buoyancy loss, such as along the sea ice edge south of the Denmark Strait for the NETJ or in the core of the jet for NWTJ.

By using 20 winters of model output from a dynamically complex ocean model driven by a fully coupled high-resolution atmosphere model that explicitly represents mesoscale winds, we can analyze the ocean's response to many different types of events over a long period. Patterns with northerly flow drive MLD deepening in the Irminger Sea regardless of the wind direction at Cape Farewell and the resulting type of tip jet, but the locations of MLD deepening differ based on the location of the maximum buoyancy loss. Additionally, the mixed layer deepens in both the Labrador and Irminger Seas for patterns with westerly flow at Cape Farewell. Frequency of wind patterns with westerly tip jets and strong barrier flow is significantly positively correlated with deeper maximum MLDs in a season in both the Irminger and Labrador Seas, while easterly tip jets with southerly flow are significantly negatively correlated with deepest maximum MLDs (Fig. 8). Therefore, westerly tip jets with strong northerly, barrier flow are most likely to cause the deepest MLD formation.

The similarity between wind pattern and buoyancy loss, discussed in the previous paragraph, suggests that correctly simulating the meridional overturning depends on accurately simulating both spatial features and frequency of the mesoscale wind. The wind patterns in this study (Fig. 2) are similar to those identified by Moore (2014) using the North American Regional Reanalysis $(32 \mathrm{~km})$ and by DuVivier and Cassano (2015a) using ERA-Interim $(150 \mathrm{~km})$ and the WRF Model $(50 \mathrm{~km})$. In particular, the top wind patterns in the right column of Fig. 2 are similar to those in DuVivier and Cassano (2015a) that are positively correlated with the North Atlantic Oscillation (NAO), so it follows that the patterns in the top-right panel of Fig. 2 are also positively correlated with the NAO. Because these patterns have the largest widespread buoyancy loss (Fig. 3), it is 
expected that in years with a strongly positive NAO index deep convection would be more likely to take place in the Irminger Sea and Labrador Sea, as has been suggested by other studies (Pickart et al. 2003b; Våge et al. 2009b). However, even in low NAO index years, open-ocean convection has been observed (Våge et al. 2008), likely because multiple wind patterns have large localized buoyancy loss.

In addition to favorable interannual variability in wind patterns, high-resolution atmospheric forcing increases the meridional overturning circulation (Jung et al. 2014; Holdsworth and Myers 2015). This study uses an atmosphere model with $50-\mathrm{km}$ horizontal grid spacing, the lowest resolution that captures mesoscale wind features, but using an atmospheric resolution of $10 \mathrm{~km}$ is better for representing mesoscale winds and turbulent flux processes (DuVivier and Cassano 2013). Hughes and Cassano (2015) and Moore et al. (2015) both show that using high model resolution is important for simulating the wind field in regions of complex topography like the Denmark Strait, while Harden and Renfrew (2012) show that the maxima in wind speed in the Denmark Strait is the result of topographically complex promontories. Simulating the strength of barrier winds is important for driving both the turbulent fluxes and also the strength of the cyclonic wind stress curl that preconditions the Irminger Sea for convection (DuVivier and Cassano 2015b). The ocean response may be enhanced or more distinct for particular wind patterns when forced with a higher-resolution atmosphere that has a more detailed and higher-magnitude wind field (Hughes and Cassano 2015). Therefore, using highresolution coupled models is important for simulating both the wind and flux processes, and it is expected that as regional and global coupled models increase in resolution the frequency of open-ocean convection and magnitude of meridional overturning may increase.

Compared to observations in the southern Irminger Sea basin, RASM simulates MLD development throughout winter and deepest MLD in a season reasonably well (Fig. 5). Typical modeled MLDs in the Irminger Sea are approximately $400 \mathrm{~m}$ but can exceed $800 \mathrm{~m}$ in particular years. In general, there is widespread MLD deepening in the Irminger Sea following northerly wind events that also have the largest buoyancy fluxes, while southerly wind events result in shoaling of the MLD or a mix of deepening and shoaling (Fig. 6). Longer-duration NETJs and NWTJs are shown to drive MLD deepening over a larger spatial area and with greater magnitude in regions of large buoyancy loss than short-duration events of the same type (Figs. 7c,d), indicating that persistent atmospheric forcing enhances the ocean response. Evaluation of the modeled upper-ocean hydrography, including estimates of mixed layer depth, with in situ observations is the focus of a separate study aimed at better understanding how RASM captures ocean hydrography and processes in different regions.

While this study has addressed many questions regarding the thermodynamic impact of different mesoscale winds on the ocean, questions still remain. This study has not addressed the impact of ocean eddies and dynamics of the marginal ice zone on convective processes (e.g., McGeehan and Maslowski 2011), preconditioning before different events, and other mechanical influences on the MLD, such as Ekman pumping or suction due to wind stress curl or bathymetric effects. Future work will more thoroughly address the oceanic impact by mechanical processes, sea ice edge location, and subtle connections between different types of wind patterns on ocean preconditioning. Additionally, this study indicates possible implications of how meridional overturning may change in a warmer climate. If the hydrologic cycle in the Arctic intensifies, then increased precipitation and terrestrial runoff may modify the haline contributions to buoyancy loss. Additionally, changes in sea surface temperature or ocean surface salinity may impact the relative contributions of the thermal and haline contributions to buoyancy loss in undetermined ways.

Acknowledgments. This research was supported by the U.S. Department of Energy (DOE) Grants DE-FG0207ER64462, DE-SC0006178, DE-SC0005783, DE-FG0207ER64460, and DE-SC0006856 and NSF Grants PLR 1107788 and ARC1107788, and computational resources were provided by the Department of Defense (DOD) High Performance Computing Modernization Program (HPCMP). WRF Model boundary conditions have been derived from the ERA-Interim dataset provided by the European Centre for Medium-Range Weather Forecasts. The ERA-Interim data for this manuscript are available on the Research Data Archive at the National Center for Atmospheric Research, Computational and Information Systems Laboratory (ERA-I: http://rda.ucar.edu/datasets/ ds627.0/; CFSR: http://rda.ucar.edu/datasets/ds093.1/). The following members of the RASM development team have not contributed directly to the analysis within this paper but have provided invaluable advice on the broader model: Xubin Zeng, William Lipscomb, Michael Brunke, and William Gutowski. We also appreciate the feedback from three anonymous reviewers who have helped improve this manuscript. Data are available from the authors upon request.

\section{REFERENCES}

Bacon, S., W. J. Gould, and Y. Jia, 2003: Open-ocean convection in the Irminger Sea. Geophys. Res. Lett., 30, 1246, doi:10.1029/ 2002 GL016271. 
Cassano, E. N., J. M. Glisan, J. J. Cassano, W. J. Gutowski Jr., and M. W. Seefeldt, 2015: Self-organizing map analysis of widespread temperature extremes in Alaska and Canada. Climate Res., 62, 199-218, doi:10.3354/cr01274.

Cassano, J. J., P. Uotila, A. H. Lynch, and E. N. Cassano, 2007: Predicted changes in synoptic forcing of net precipitation in large Arctic river basins during the 21st century. J. Geophys. Res., 112, G04S49, doi:10.1029/2006JG000332.

—, M. Higgins, and M. Seefeldt, 2011: Performance of the Weather Research and Forecasting (WRF) Model for monthlong pan-Arctic simulations. Mon. Wea. Rev., 139, 3469-3488, doi:10.1175/MWR-D-10-05065.1.

Centurioni, L. R., and W. J. Gould, 2004: Winter conditions in the Irminger Sea observed with profiling floats. J. Mar. Res., 62, 313-336, doi:10.1357/0022240041446209.

Clarke, R. A., and J.-C. Gascard, 1983: The formation of Labrador Sea water. Part I: Large-scale processes. J. Phys. Oceanogr., 13, 1764-1778, doi:10.1175/1520-0485(1983)013<1764: TFOLSW $>2.0 . \mathrm{CO} ; 2$.

Condron, A., and I. A. Renfrew, 2013: The impact of polar mesoscale storms on northeast Atlantic Ocean circulation. Nat. Geosci., 6, 34-37, doi:10.1038/ngeo1661.

Craig, A. P., M. Vertenstein, and R. Jacob, 2012: A new flexible coupler for earth system modeling developed for CCSM4 and CESM1. Int. J. High Perform. Comput. Appl., 26, 31-42, doi:10.1177/1094342011428141.

Dee, D. P., and Coauthors, 2011: The ERA-Interim reanalysis: Configuration and performance of the data assimilation system. Quart. J. Roy. Meteor. Soc., 137, 553-597, doi:10.1002/ qj.828.

De Jong, M. F., H. M. van Aken, K. Våge, and R. S. Pickart, 2012: Convective mixing in the central Irminger Sea: 2002-2010. Deep-Sea Res. I, 63, 36-51, doi:10.1016/j.dsr.2012.01.003.

Doyle, J. D., and M. A. Shapiro, 1999: Flow response to large-scale topography: The Greenland tip jet. Tellus, 51A, 728-748, doi:10.1034/j.1600-0870.1996.00014.x.

DuVivier, A. K., and J. J. Cassano, 2013: Evaluation of WRF Model resolution on simulated mesoscale winds and surface fluxes near Greenland. Mon. Wea. Rev., 141, 941-963, doi:10.1175/MWR-D-12-00091.1.

— , and - 2015a: Comparison of wintertime mesoscale winds over the ocean around southeastern Greenland in WRF and ERA-Interim. Climate Dyn., doi:10.1007/s00382-015-2697-8, in press.

$\longrightarrow$, and $-2015 \mathrm{~b}$ : Exploration of turbulent heat fluxes and wind stress curl in WRF and ERA-Interim during wintertime mesoscale wind events around southeastern Greenland. J. Geophys. Res., 120, 3593-3609, doi:10.1002/ 2014JD022991.

Dyer, A. J., and B. B. Hicks, 1970: Flux-gradient relationships in the constant flux layer. Quart. J. Roy. Meteor. Soc., 96, 715721, doi:10.1002/qj.49709641012.

Gascard, J.-C., and R. A. Clarke, 1983: The formation of Labrador Sea Water. II: Mesoscale and smaller-scale processes. J. Phys. Oceanogr., 13, 1779-1797, doi:10.1175/1520-0485(1983)013<1779: TFOLSW $>2.0 . \mathrm{CO} ; 2$.

Grell, G. A., and D. Dévényi, 2002: A generalized approach to parameterizing convection combining ensemble and data assimilation techniques. Geophys. Res. Lett., 29, 38-1-38-4, doi:10.1029/2002GL015311.

Haine, T. W. N., S. Zhang, G. W. K. Moore, and I. A. Renfrew, 2009: On the impact of high-resolution, high-frequency meteorological forcing on Denmark Strait ocean circulation.
Quart. J. Roy. Meteor. Soc., 135, 2067-2085, doi:10.1002/ qj.505.

Harden, B. E., and I. A. Renfrew, 2012: On the spatial distribution of high winds off southeast Greenland. Geophys. Res. Lett., 39, L14806, doi:10.1029/2012GL052245.

,,-- and G. N. Petersen, 2011: A climatology of wintertime barrier winds off southeast Greenland. J. Climate, 24, 47014717, doi:10.1175/2011JCLI4113.1.

Hewitson, B. C., and R. G. Crane, 2002: Self-organizing maps: Applications to synoptic climatology. Climate Res., 22, 13-26, doi: $10.3354 / \mathrm{cr} 022013$.

Holdsworth, A. M., and P. G. Myers, 2015: The influence of highfrequency atmospheric forcing on the circulation and deep convection of the Labrador Sea. J. Climate, 28, 4980-4996, doi:10.1175/JCLI-D-14-00564.1.

Holland, M. M., D. A. Bailey, B. Briegleb, B. Light, and E. Hunke, 2012: Improved sea ice shortwave radiation physics in CCSM4: The impact of melt ponds and aerosols on Arctic sea ice. J. Climate, 25, 1413-1430, doi:10.1175/ JCLI-D-11-00078.1.

Hong, S.-Y., Y. Noh, and J. Dudhia, 2006: A new vertical diffusion package with an explicit treatment of entrainment processes. Mon. Wea. Rev., 134, 2318-2341, doi:10.1175/ MWR3199.1.

Hughes, M., and J. J. Cassano, 2015: The climatological distribution of extreme Arctic winds and implications for ocean and sea ice processes. J. Geophys. Res. Atmos., 120, 7358-7377, doi:10.1002/ $2015 J D 023189$.

Hunke, E. C., and W. H. Lipscomb, 2010: CICE: The Los Alamos Sea Ice Model Documentation and Software User's Manual version 5.0. Los Alamos National Laboratory Tech. Rep. LACC-06-012, 115 pp.

Iacono, M. J., J. S. Delamere, E. J. Mlawer, M. W. Shephard, S. A. Clough, and W. D. Collins, 2008: Radiative forcing by longlived greenhouse gases: Calculations with the AER radiative transfer models. J. Geophys. Res., 113, D13103, doi:10.1029/ 2008JD009944.

Jung, T., S. Serrar, and Q. Wang, 2014: The oceanic response to mesoscale atmospheric forcing. Geophys. Res. Lett., 41, 12551260, doi:10.1002/2013GL059040.

Killworth, P. D., 1983: Deep convection in the World Ocean. Rev. Geophys., 21, 1-26, doi:10.1029/RG021i001p00001.

Kohonen, T., 2001: Self-Organizing Maps. 3rd ed. Springer, 501 pp.

Kolstad, E., 2008: A QuikSCAT climatology of ocean surface winds in the Nordic seas: Identification of features and comparison with the NCEP/NCAR reanalysis. J. Geophys. Res., 113, D11106, doi:10.1029/2007JD008918.

Large, W. G., J. C. McWilliams, and S. C. Doney, 1994: Oceanic vertical mixing: A review and a model with a nonlocal boundary layer parameterization. Rev. Geophys., 32, 363-403, doi:10.1029/94RG01872.

Lavender, K. L., R. E. Davis, and W. B. Owens, 2002: Observations of open-ocean deep convection in the Labrador Sea from subsurface floats. J. Phys. Oceanogr., 32, 511-526, doi:10.1175/ 1520-0485(2002)032<0511:OOOODC > 2.0.CO; 2.

Lazier, J., R. Hendry, A. Clarke, I. Yashayaev, and P. Rhines, 2002: Convection and restratification in the Labrador Sea, 1990-2000. Deep-Sea Res. I, 49, 1819-1835, doi:10.1016/ S0967-0637(02)00064-X.

Liu, Y., R. H. Weisberg, and R. He, 2006: Sea surface temperature patterns on the West Florida Shelf using growing hierarchical self-organizing maps. J. Atmos. Oceanic Technol., 23, 325-338, doi:10.1175/JTECH1848.1. 
Marshall, J., and F. Schott, 1999: Open-ocean convection: Observations, theory, and models. Rev. Geophys., 37, 1-64, doi:10.1029/98RG02739.

- , and A. Plumb, 2007: Atmosphere, Ocean and Climate Dynamics: An Introductory Text. 1st ed. Academic Press, $344 \mathrm{pp}$.

Martin, R., and G. W. K. Moore, 2007: Air-sea interaction associated with a Greenland reverse tip jet. Geophys. Res. Lett., 34, L24802, doi:10.1029/2007GL031093.

Maslowski, W., J. C. Kinney, M. Higgins, and A. Roberts, 2012: The future of Arctic sea ice. Annu. Rev. Earth Planet. Sci., 40, 625-654, doi:10.1146/annurev-earth-042711-105345.

McGeehan, T., and W. Maslowski, 2011: Impact of shelf-basin freshwater transport on deep convection in the western Labrador Sea. J. Phys. Oceanogr., 41, 2187-2210, doi:10.1175/ JPO-D-11-01.1.

Moore, G. W. K., 2003: Gale force winds over the Irminger Sea to the east of Cape Farewell, Greenland. Geophys. Res. Lett., 30, 1894, doi:10.1029/2003GL018012.

—, 2012: A new look at Greenland flow distortion and its impact on barrier flow, tip jets and coastal oceanography. Geophys. Res. Lett., 39, L22806, doi:10.1029/ 2012GL054017.

— , 2014: Mesoscale structure of Cape Farewell tip jets. J. Climate, 27, 8956-8965, doi:10.1175/JCLI-D-14-00299.1.

- , and I. Renfrew, 2005: Tip jets and barrier winds: A QuikSCAT climatology of high wind speed events around Greenland. J. Climate, 18, 3713-3725, doi:10.1175/ JCLI3455.1.

_ K. Alverson, and I. A. Renfrew, 2002: A reconstruction of the air-sea interaction associated with the Weddell polynya. J. Phys. Oceanogr., 32, 1685-1698, doi:10.1175/1520-0485(2002)032<1685: AROTAS $>2.0 . \mathrm{CO} ; 2$.

— , R. S. Pickart, I. A. Renfrew, and K. Våge, 2014: What causes the location of the air-sea turbulent heat flux maximum over the Labrador Sea? Geophys. Res. Lett., 3628-3635, doi:10.1002/2014GL059940.

_ I. A. Renfrew, B. E. Harden, and S. H. Mernild, 2015: The impact of resolution on the representation of southeast Greenland barrier winds and katabatic flows: Greenland flow distortion. Geophys. Res. Lett., 42, 3011-3018, doi:10.1002/ 2015GL063550.

Morrison, H., G. Thompson, and V. Tatarskii, 2009: Impact of cloud microphysics on the development of trailing stratiform precipitation in a simulated squall line: Comparison of oneand two-moment schemes. Mon. Wea. Rev., 137, 991-1007, doi:10.1175/2008MWR2556.1.

Oltmanns, M., F. Straneo, G. W. K. Moore, and S. H. Mernild, 2014: Strong downslope wind events in Ammassalik, Southeast Greenland. J. Climate, 27, 977-993, doi:10.1175/ JCLI-D-13-00067.1.

Paulson, C. A., 1970: The mathematical representation of wind speed and temperature profiles in the unstable atmospheric surface layer. J. Appl. Meteor., 9, 857-861, doi:10.1175/ 1520-0450(1970)009<0857:TMROWS > 2.0.CO;2.

Petersen, G. N., and I. A. Renfrew, 2009: Aircraft-based observations of air-sea fluxes over Denmark Strait and the Irminger Sea during high wind speed conditions. Quart. J. Roy. Meteor Soc., 135, 2030-2045, doi:10.1002/qj.355.

Pickart, R. S., M. A. Spall, M. H. Ribergaard, G. Moore, and R. F. Milliff, 2003a: Deep convection in the Irminger Sea forced by the Greenland tip jet. Nature, 424, 152-156, doi:10.1038/ nature 01729 .
— F. Straneo, and G. Moore, 2003b: Is Labrador Sea Water formed in the Irminger basin? Deep-Sea Res. I, 50, 23-52, doi:10.1016/S0967-0637(02)00134-6.

- K. Våge, G. Moore, I. A. Renfrew, M. H. Ribergaard, and H. C. Davies, 2008: Convection in the western North Atlantic sub-polar gyre: Do small-scale wind events matter? Arctic-Subarctic Ocean Fluxes: Defining the Role of the Northern Seas in Climate, R. R. Dickson, J. Meincke, and P. B. Rhines, Eds., Springer, 629-652, doi:10.1007/ 978-1-4020-6774-7.

Renfrew, I. A., and G. W. K. Moore, 1999: An extreme cold-air outbreak over the Labrador Sea: Roll vortices and air-sea interaction. Mon. Wea. Rev., 127, 2379-2394, doi:10.1175/ 1520-0493(1999)127<2379:AECAOO > 2.0.CO;2.

G. N. Petersen, D. A. J. Sproson, G. W. K. Moore, H. Adiwidjaja, S. Zhang, and R. North, 2009: A comparison of aircraft-based surface-layer observations over Denmark Strait and the Irminger Sea with meteorological analyses and QuikSCAT winds. Quart. J. Roy. Meteor. Soc., 135, 2046-2066, doi:10.1002/qj.444.

Reusch, D. B., R. B. Alley, and B. C. Hewitson, 2005: Relative performance of self-organizing maps and principal component analysis in pattern extraction from synthetic climatological data. Polar Geogr., 29, 188-212, doi:10.1080/ 789610199.

Roberts, A., J. J. Cassano, R. Doscher, L. Hinzman, M. M. Holland, H. Mitsudera, A. Sumi, and J. E. Walsh, 2010: A science plan for regional arctic system modeling: A report by the Arctic Research Community for the National Science Foundation Office of Polar Programs. International Arctic Research Center Tech. Rep. 10-0001, 47 pp. [Available online at http://www.iarc.uaf.edu/sites/default/files/publications/ reports/IARCTP10-0001.pdf.]

— , and Coauthors, 2015: Simulating transient ice-ocean Ekman transport in the Regional Arctic System Model and Community Earth System Model. Ann. Glaciol., 56, 211-228, doi:10.3189/2015AoG69A760.

Sathiyamoorthy, S., and G. W. K. Moore, 2002: Buoyancy flux at Ocean Weather Station Bravo. J. Phys. Oceanogr., 32, 458-474, doi:10.1175/1520-0485(2002)032<0458:BFAOWS >2.0.CO;2.

Schmitt, R. W., P. S. Bogden, and C. E. Dorman, 1989: Evaporation minus precipitation and density fluxes for the North Atlantic. J. Phys. Oceanogr., 19, 1208-1221, doi:10.1175/ 1520-0485(1989)019<1208:EMPADF > 2.0.CO;2.

Schuenemann, K. C., J. J. Cassano, and J. Finnis, 2009: Synoptic forcing of precipitation over Greenland: Climatology for 1961-99. J. Hydrometeor., 10, 60-78, doi:10.1175/ 2008JHM1014.1.

Sheridan, S. C., and C. C. Lee, 2011: The self-organizing map in synoptic climatological research. Prog. Phys. Geogr., 35, 109119, doi:10.1177/0309133310397582.

Shkolnik, I. M., and S. V. Efimov, 2013: Cyclonic activity in high latitudes as simulated by a regional atmospheric climate model: Added value and uncertainties. Environ. Res. Lett., 8, 045007, doi:10.1088/1748-9326/8/4/045007.

Skamarock, W. C., and Coauthors, 2008: A description of the Advanced Research WRF version 3. NCAR Tech. Note NCAR/TN-475+STR, 113 pp., doi:10.5065/D68S4MVH.

Spall, M. A., and R. S. Pickart, 2003: Wind-driven recirculations and exchange in the Labrador and Irminger Seas*. J. Phys. Oceanogr., 33, 1829-1845, doi:10.1175/2384.1.

Sproson, D. A. J., I. A. Renfrew, and K. J. Heywood, 2008: Atmospheric conditions associated with oceanic convection in 
the south-east Labrador Sea. Geophys. Res. Lett., 35, L06601, doi:10.1029/2007GL032971.

_ —_ and _ 2010: A parameterization of Greenland's tip jets suitable for ocean or coupled climate models. J. Geophys. Res., 115, C08022, doi:10.1029/2009JC006002.

Tilinina, N., S. K. Gulev, and D. H. Bromwich, 2014: New view of Arctic cyclone activity from the Arctic system reanalysis. Geophys. Res. Lett., 41, 1766-1772, doi:10.1002/2013GL058924.

Våge, K., R. S. Pickart, G. W. K. Moore, and M. H. Ribergaard, 2008: Winter mixed layer development in the central Irminger Sea: The effect of strong, intermittent wind events. J. Phys. Oceanogr., 38, 541-565, doi:10.1175/ 2007JPO3678.1.
_ - and Coauthors, 2009a: Surprising return of deep convection to the subpolar North Atlantic Ocean in winter 2007-2008. Nat. Geosci., 2, 67-72, doi:10.1038/ngeo382.

- T. Spengler, H. C. Davies, and R. S. Pickart, 2009b: Multievent analysis of the westerly Greenland tip jet based upon 45 winters in ERA-40. Quart. J. Roy. Meteor. Soc., 135, 19992011, doi:10.1002/qj.488.

_ , and Coauthors, 2011: The Irminger Gyre: Circulation, convection, and interannual variability. Deep-Sea Res. I, 58, 590 614, doi:10.1016/j.dsr.2011.03.001.

Webb, E. K., 1970: Profile relationships: The log-linear range, and extension to strong stability. Quart. J. Roy. Meteor. Soc., 96, 67-90, doi:10.1002/qj.49709640708. 